خصائص اللاتماثل (الكسور) والتأثيرات الجاتبية في ضوء المسح المقاومي السمتي ضمن سهل القوش - شمال العراق

\author{
يوسف فرنسيس اقليمس \\ مركز بحوث السدود و الموارد المائية \\ جامعة الموصل \\ مروان متعب \\ جامعة الموصل مرن \\ كلبة العلوم \\ قسم علوم الأرض

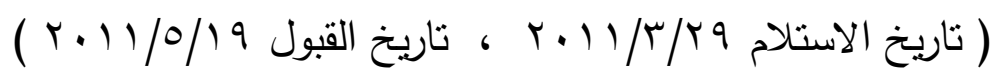

\title{
الملخص
}

يقع سهل ألقوش على بعد · ع كم شمال مدينة الموصل ويحاط بعدة طيات محدبة طوروسية الاتجاه (ثرق-غرب) ويفصل بين هذه الطيات طية مقعرة واسعة تقع تحت السهل، حيث تتكثف في لب الطيات البعل صخور الايوسين الأوسط- الاعلى تقع فوقها تكاوين الفتحة وانجانة والمقدادية. اجري المسح الحقلي لتسجيل قياسات المقاومة الأرضية باختيار ثلاثة مواقع في منطقة الأنية الدراسة

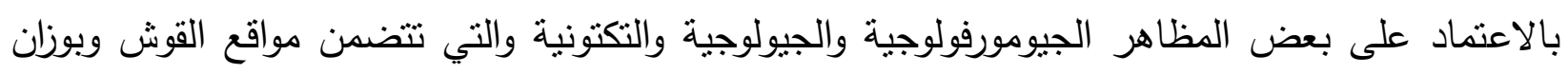

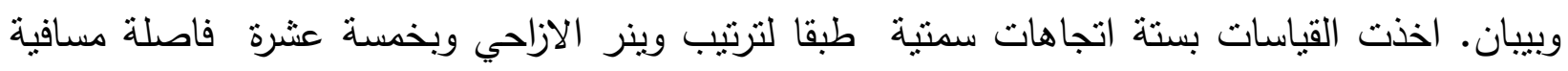

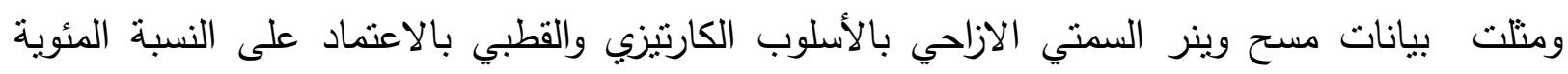

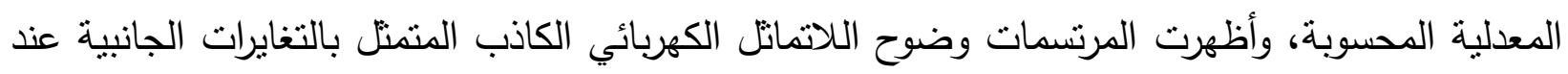

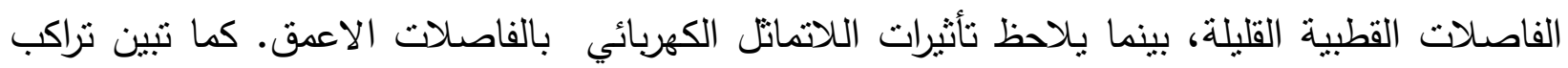

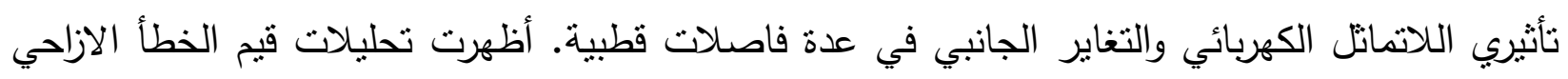

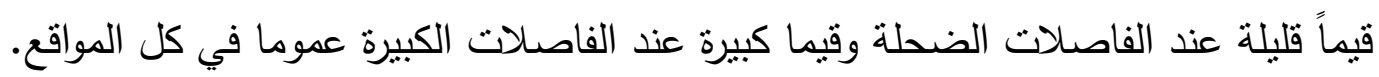
أبرزت مواقع منطقة الدراسة ترددات واتجاهات وميل منباين للكسور لمجاميع موازية وعمودية لمحور الطيات وتبين انها ذات نوعين شاقولي ومتوسطة الميل، فضلاً عن ملاحظة كسور رئيسة تمند لعدة

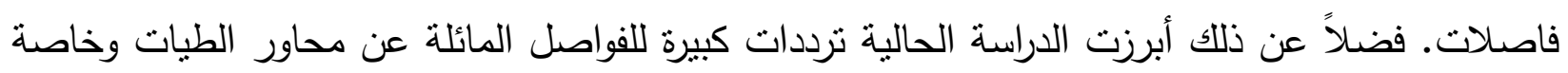
في موقعي القوش وبوزان. 
مروان متعب و يوسف فرنسيس اقليمس

\section{Fracture Anisotropy Characterization and Lateral Effects from Azimuthal Resitivity Survey in Alqosh Plain- North Iraq}

\author{
Marwan Mutib \\ Department of Geology \\ College of Science \\ Mosul University
}

\author{
Yousif Francis Eclimes \\ Dams and Water Resources \\ Research Center
}

\section{ABSTRACT}

Alqosh plain lies about $40 \mathrm{~km}$ to the north of Mosul city surrounded by several Taurus anticlines (E-W direction). The anticlines are separated by a wide syncline underlying the plain .The M-U Eocene rocks are exposed in the core of those anticlines which are overlain by Fat'ha, Injana and Meqdadya Formations.

The field survey of the earth resistance measurements was carried out at three locations (Alqosh, Boawzan, Bayban) in the study area, depending upon some geomorphological, geological and geotectonic features. Three azimuthal directions are used appling Offset Wenner Array (OWA) with fifteen spacing intervals.

The OWA survey was represented by cartesian and polar graphs depending on the calculated mean percentage. The results displayed pseudo electrical anisotropy representing by lateral variations at small electrode spacings, while electrical anisotropy effects are shown in large spacings..

The present study indicated varied fractures having frequencies, directions and dips that are parallel and vertical to the structural axes with vertical and medium dips. as well as, minor and medium fractures extending for several spacings. The current study showed large frequency fractures that are inclined to the fold axes especially in Alqosh and Bawzan. In addition, an inverse relationship appeared between electrical anisotropy frequencies and lateral variations in the study area.

\section{المقدمة}

يقع سهل ألقوش على بعد ·ـ كم شمال مدينة الموصل ويغطي السهل مساحة أكثر من · • اكم مربع

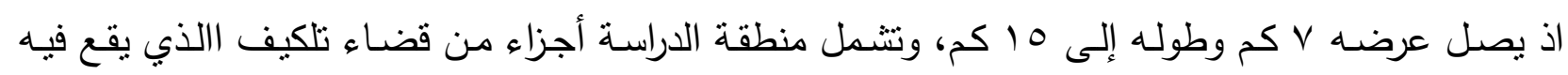

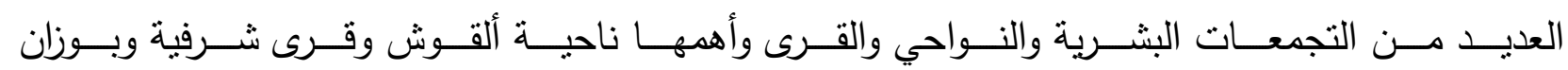

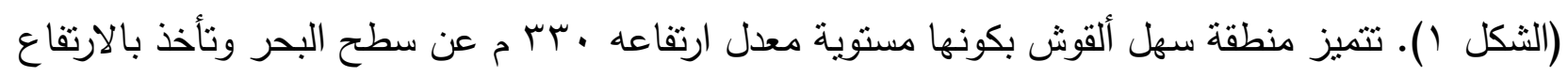

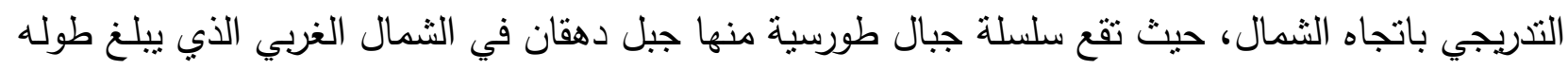

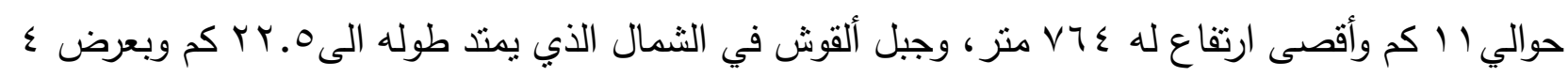

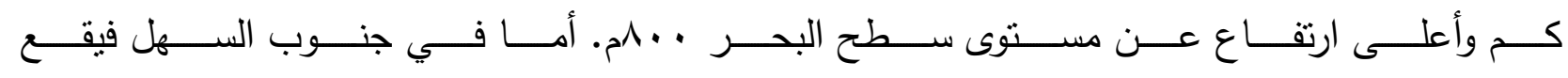


rV خصائص اللاتماثل (الكسور) والتأثيرات الجانبية في ضوء المسح المقاومي السمتي...

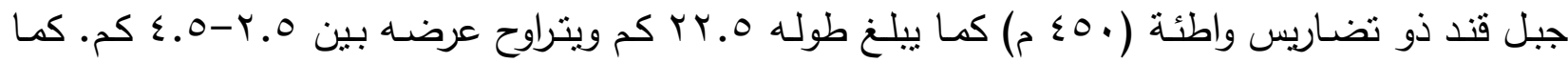
يلاحظ ان أنماط التصريف في الجبال الثمالية من النوع الثـجيرية أما في جبل قند في الجنوب فان نمط التصريف من النوع المتوازي وهنالك العديد من الوديان التي تخترق منطقة الدراسة الأول.

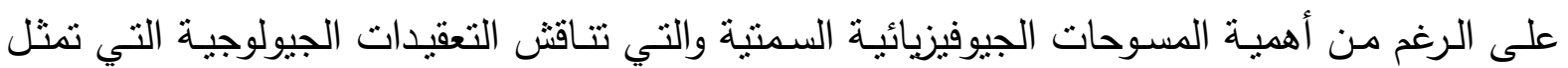
تأثثرات اللاتجانس واللاتمانل الكهربائي في الطبقات الصخرية والتي تسمى بالضوضاء الجيولوجية، لم بتطرق اليها الباحثين الجيوفيزيائيين في العراق بالرغم من شيوع استخدامها في العديد من الدراسات العالمية باسثناء قيام (متعب وآخرون 9 × · r) باستخدام المسح المقاومي السمتي في دراسة بيئية محدودة لحقل المشراق - I. . تستهدف الدراسـة الحاليـة تحديد وجود اللاتمانثل الكهربـئي Anisotropy (الكسور) وتمييزهـا عن تأثنيرات التغـايرات الجانبيـة باسـتخدام تقنيـة مسـوحات سـتية ازاحيـة عميقـة بتطبيـق جس وينـر الخماسـي الأقطاب في محاولة لتحليل المقاومة بأساليب منتوعة استتادا الى الدراسـات العالمية الحديثة المنجزة في هذا

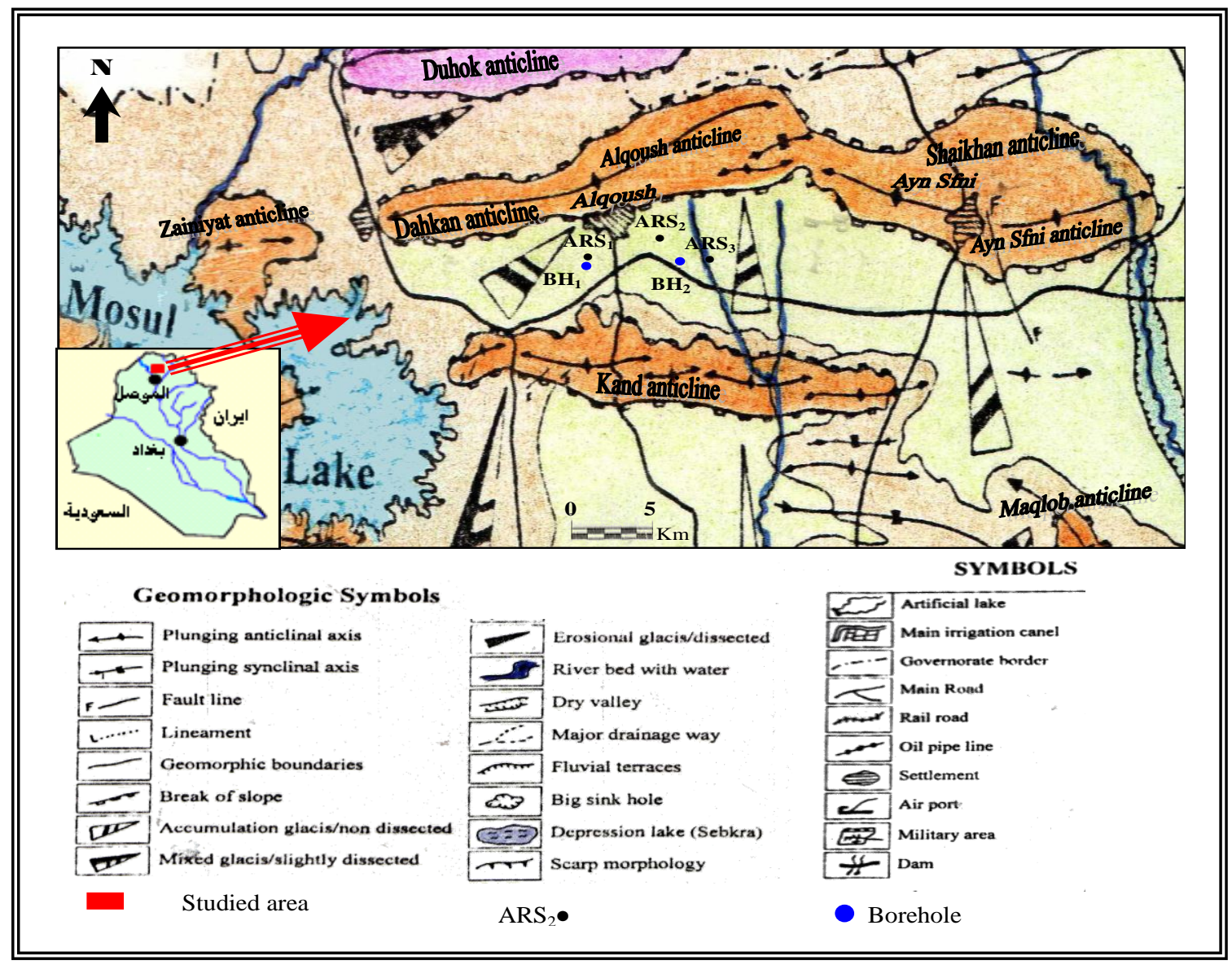

الثكل ا : موقع وطبوغرافية منطقة الدراسة والمناطق المجاورة (2007, Al-Daghastani ). 


\section{جيولوجية وهايدروجيولوجية المنطقة:}

يحبط سهل ألقوش طيات محدبة طوروسية الاتجاه (شرق-غرب) متمثلة بطيات دهقان وألقوش في

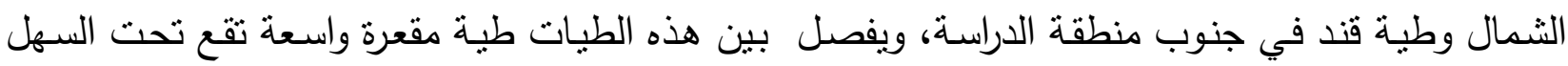

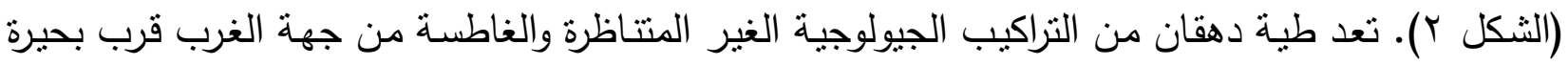

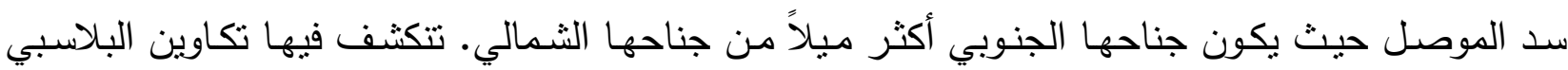
والفتحة وإنجانة فالترسبات الحديثة و ينحرف الخط المفصلي للطية في جزئه الوسطي، ثم ينحرف مرة اخرى

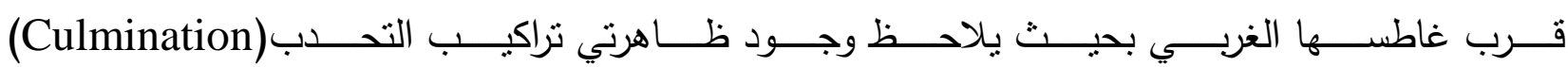
والانخفاض(Depression) بسبب تغير ميل الخط المفصلي. وعموماً يكون اتجاه الخط المحوري العام للطية

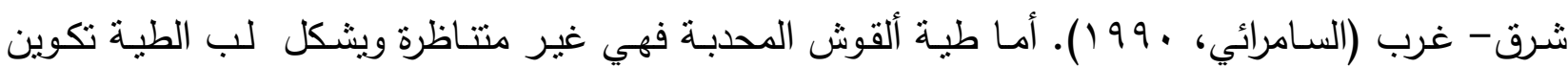

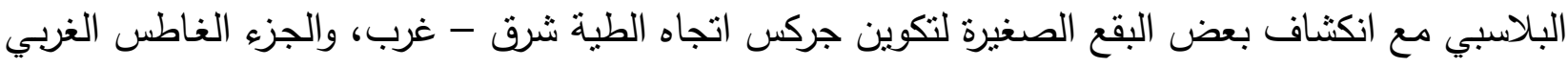

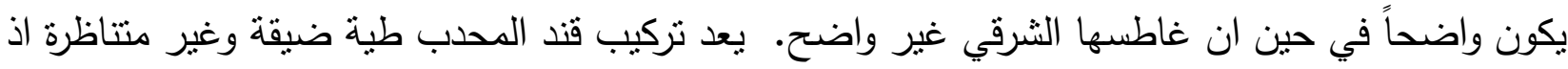

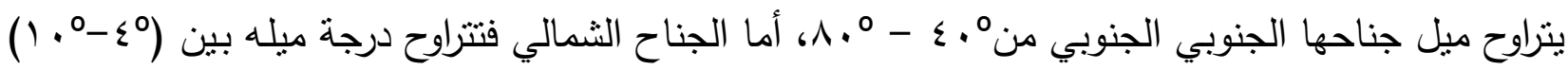

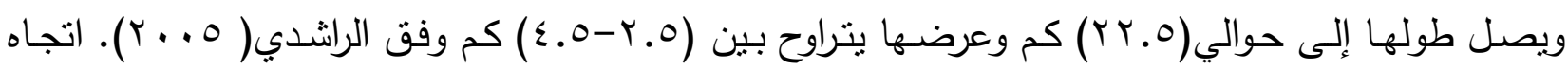
محور الطية العام (ثمال غرب - جنوب شرق)، وتحوي الطية على خمسة قباب ومعظم لب الطية متكون

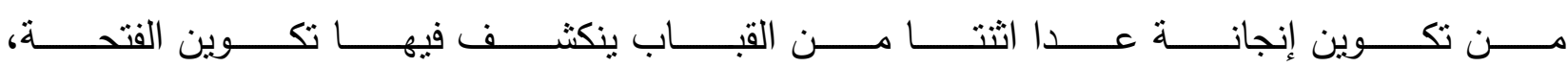

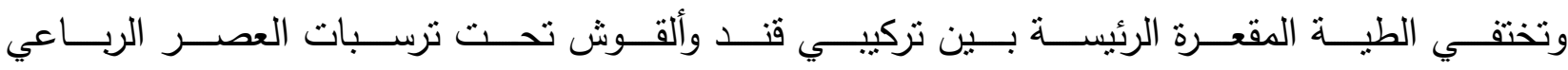

.(Sissikian et al., 1995)

تكتونيا تقع منطقة الدراسة في نطاق الطبات الواطئة ضمن نطاق جمجمال- بطمة حسب تقسيمات

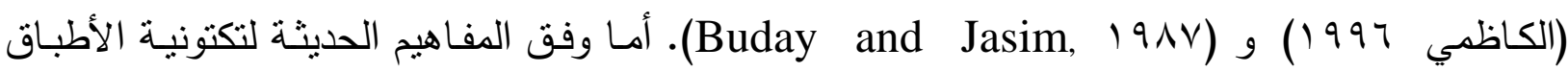
(Numan, 1997) للفورلاند الثبيه بالسطيح. طباقيا لا يظهر تكوين البلاسبي الجيري(الايوسين الأوسط - الأعلى) في مكاشف الوديان المخترقة

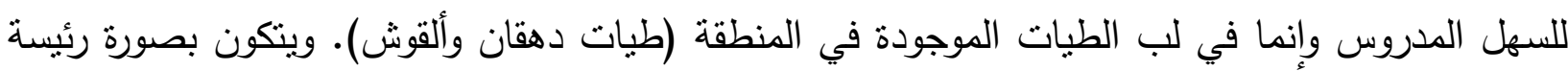
من صخور صلبة من الحجر الدولوماتي والحجر الجيري، وتستقر تعاقبات الصلصال والجبس والحجر

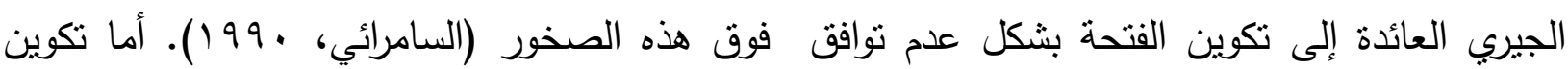
الفتحة (المايوسن الأوسط) فيتألف بصورة عامة من دورات ترسيبية متمثلة بالجبس والحجر الجيري والمارل الأخضر والأحمر، وينكثف هذا التكوين في المناطق المحيطة بالطيات الموجودة وبسمك مختلفة ويزداد عمقه كلما انتقلنا إلى مركز الطية المقعرة والتي نتشغل الغلب مساحات منطقة السهل الددروس، كما شكلت بعض الطبقات الصخرية من المارل والحجر الجيري حواجز صخرية بهيئة حزام ضيق عند تكوين الفنحة في

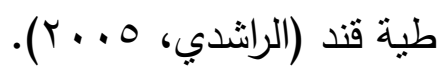


ينكثف تكوين إنجانه (المايوسين العلوي ) في منطقة الدراسة على نطاق واسع وخاصة بالقرب من

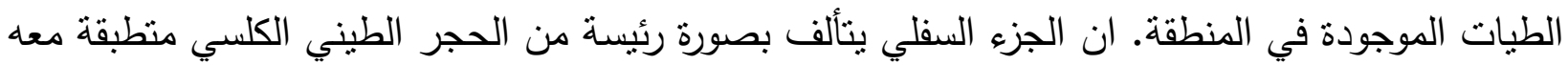
طبقات رقيقة نسبيا من الحجر الرملي الناعم. بينما يتألف الجزء العلوي من الحجر الرملي ذات ذات الحبيبات

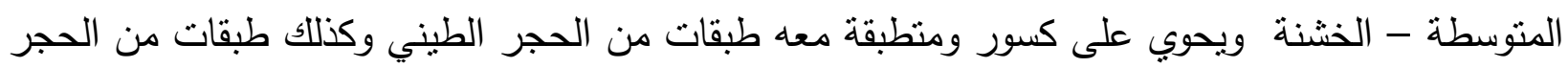
الطيني السلتي (السامرائي، .991) . ويشكل هذا التكوين في طية قند الجزء الأكبر من مكاشفه الصخرية بحيث يتألف بشكل رئيس من صخور الحجر الرملي البنية المحمرة السميكة مع حجر المارل السلتي البني

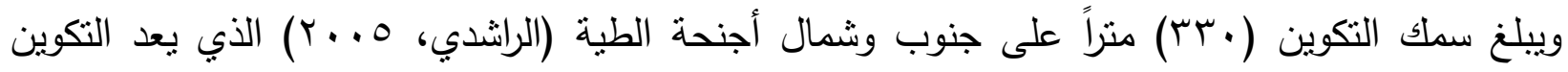
الأهم في الدراسة الحالية.

يتألف تكوين المقدادية (المايوسين الاعلى - البلايوسين) من الحجر الرملي الحصوي والحجر الرملي

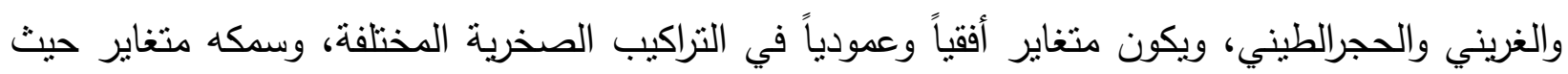
يكون في طية ألقوش حوالي (10) م (Sissikian et al., 1995). أما ترسبات العصر الرباعي فهي عبارة عن نواتج التعرية حيث تتألف من قطع صخرية مختلفة

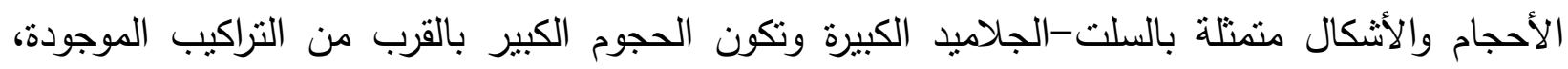
وتكون معظم مكوناتها مشتقة من التكوينات المنكثفة في المنطقة. وتتشمل على نرسبات المنحدرات وسفوح

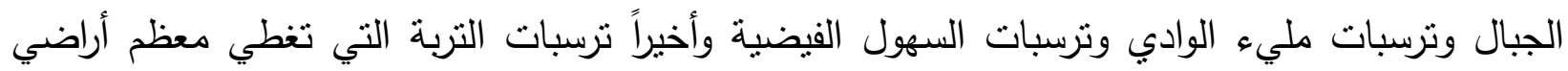

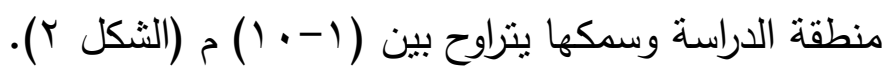
بالنظر لطبيعة التكاوين الموجودة في منطقة الدراسة والمنمنلة بتكويني إنجانه ومقدادية والترسبات

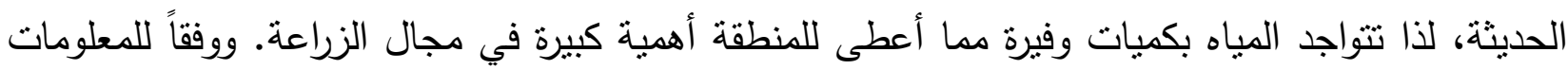

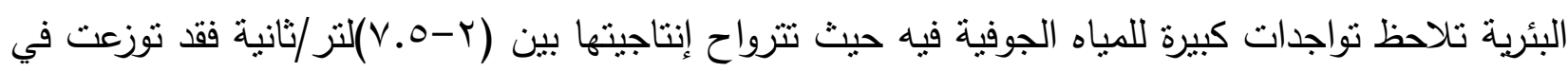

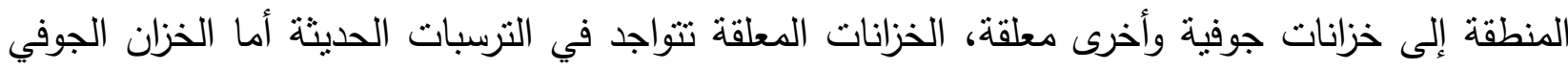
فيتواجد ضمن ترسبات تكويني مقدادية وإنجانه، وعموما تتباين سمك هذه الخزانات وأعماقها وإنتاجيتها اعتماداً على طبيعة الرواسب وتضاريسية المنطقة وكذلك كميات الأمطار الساقطة في الأحواض المغذية لهنية لها فضلاًاً عن وجود الكسور والفواصل في تكاوينها، حيث توضح المعلومات البئرية ان منسوب الماء ألاستقراري فيها

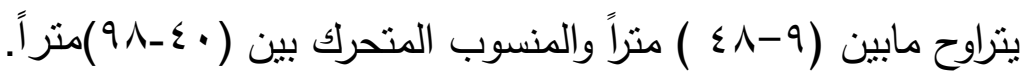

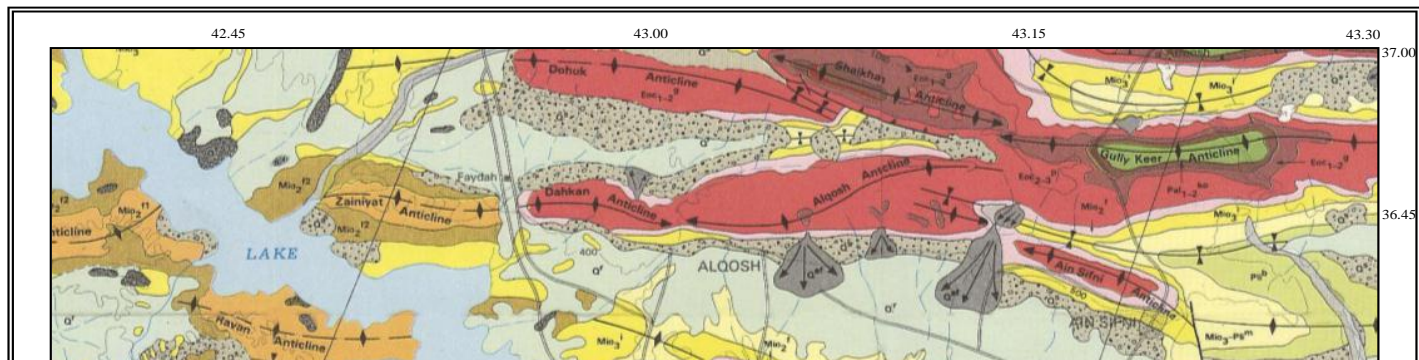


وبالنظر لمواصفات الصخور المتواجدة وخاصة صخور تكوين إنجانة ذات القيمة الهايدرولوجية العالية لذللك فمياه الخزانات الجوفية في هذا التكوين تكون ذا نوعيات جيدة وصالحة للاستخدامات البشرية والزراعية والصناعية. فمعدلات الأملاح الذائبة فيها لا تتجاوز ( . . 7 ) ملغرام/لتر وكذلك التوصيل الكهربائي يترواح بين ( . ع - • (17) مايكروموز /سم.

تمثيل وتحليل معطيات مسح المقاومة السمتي:

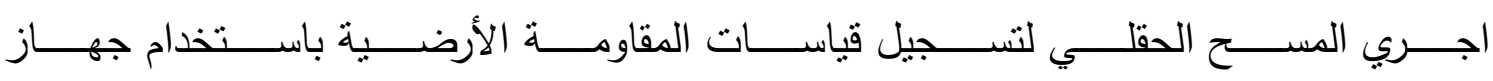
(ABEM Tetrrameter SAS 300B)

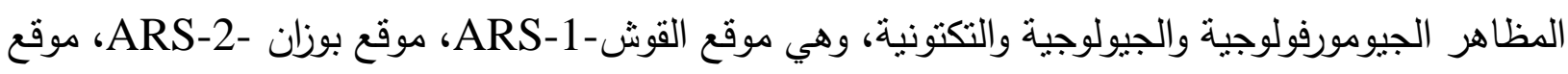

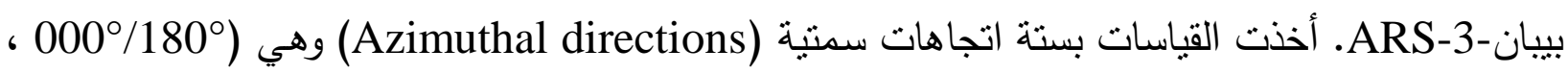

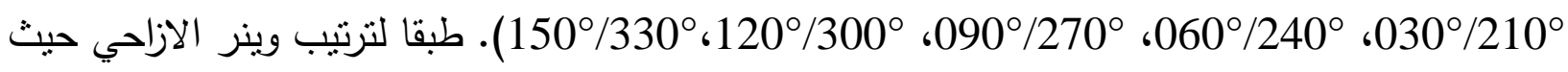

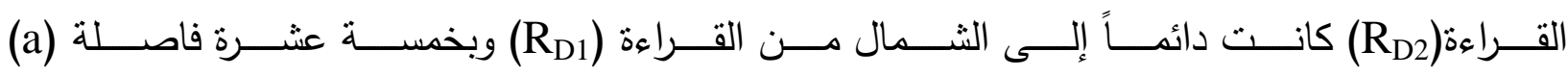

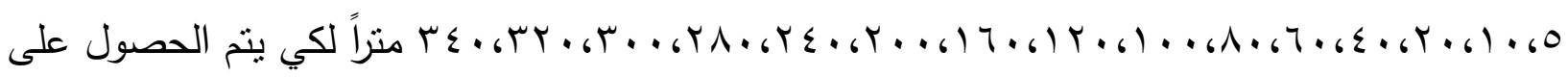

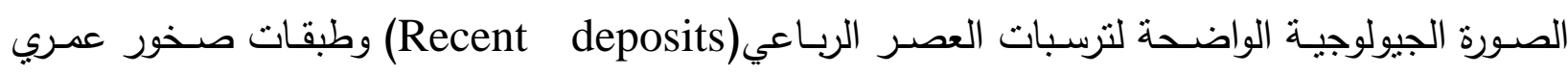

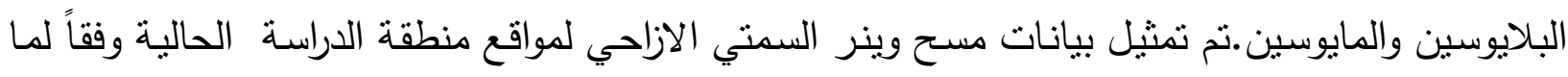

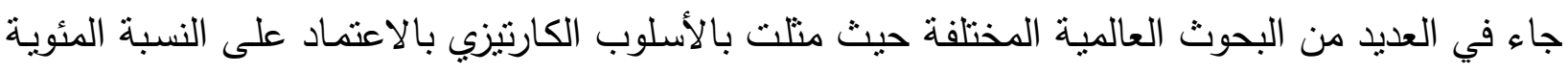

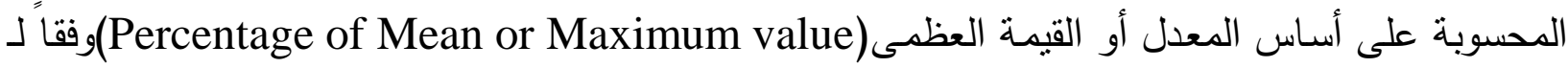


(Nunn et al., 1995)، وكذللك تم تمثيل البيانات من خلال الأسلوب القطبي (Polar Graph) والذب في استخدم عالمياً في العديد من الدراسات منها:

(Sauck and Zabik, 1992; Steinich and Marin, 1997; Watson and Barker, 1999; Busby, 2000;Wilson et al., 2000; Rayner and Bentely, 2004; Busby and Jakson, 2005; Boris, 2005; Watson and Barker, 2005; Schmutz et al., 2006; Wishart,

تظهر الأشكال الكارتيزية بشكل عام المعلومة الأفضل في التفسير البصري (Visual) اذ توضح

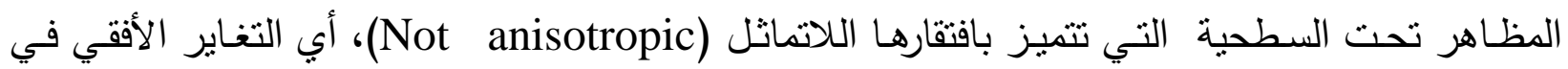
المقاومة الأرضية. أو قد يظهر ذلك التفسير ارتفاعاً وانخفاضاً (Rise and fall) لمنحنيب اتجاه المستح

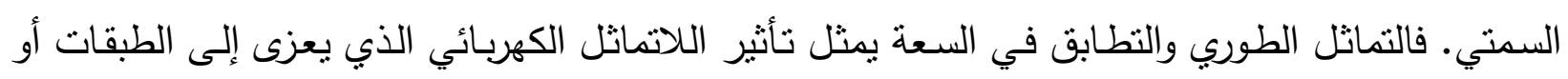

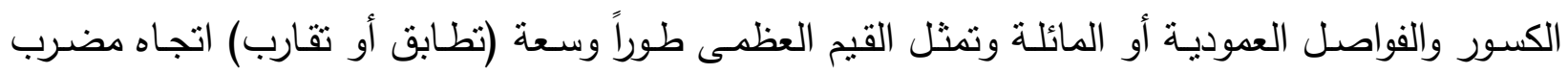

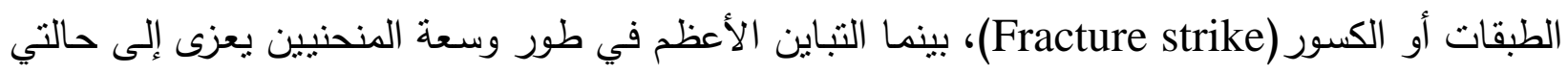

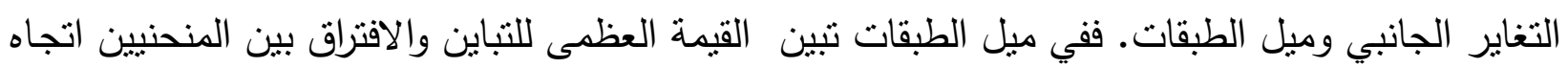

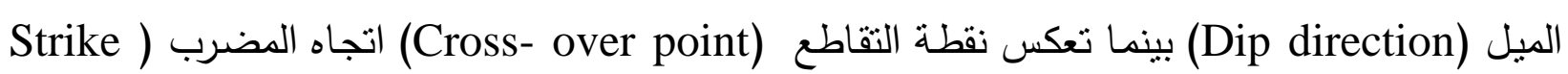
(direction

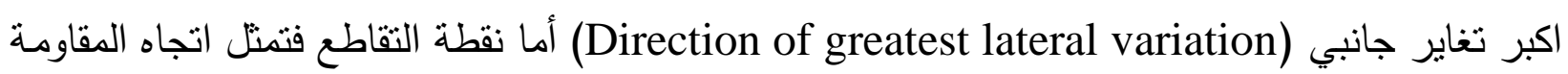
الثابتة(Direction of constant resistivity) مع إمكانية التمبيز بين التغايرات الجانبية والميل للطبقات باستخدام تحليلات الخطأ الازاحي.

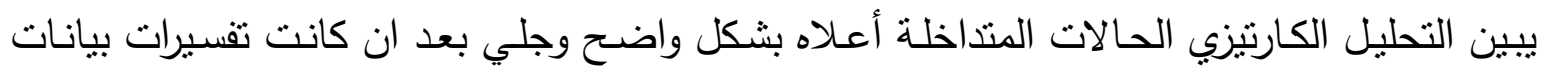

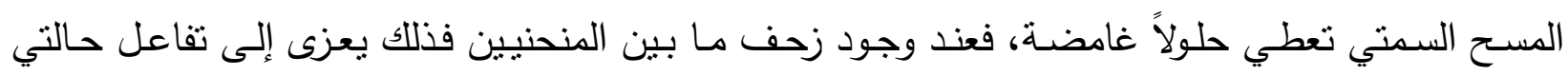

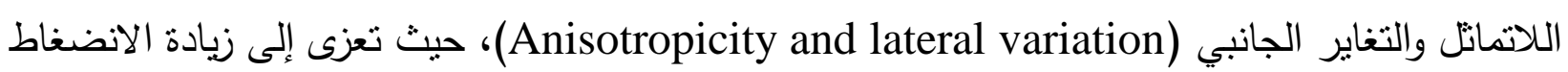

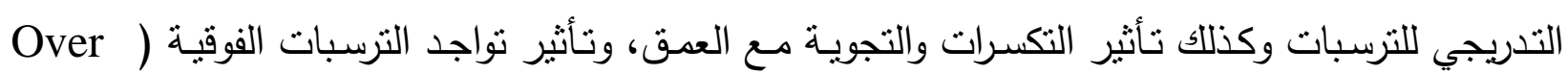
burden غامضة (Ambiguous solution) في كافة الدراسات العالمية التي تمت قبل استخدام تقنية وينر الازاحية كتقنية بديلة من قبل (Watson and Barker, 1999) حيث قام الباحثان بنطبيق هذه التقنية للتمبيز بين

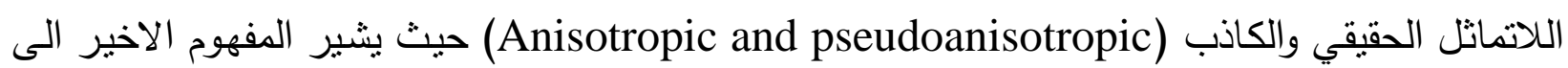
تأثير التغايرات الجانبية.

يبين التمثبل القطبي لقيمتي وينر الازاحية التوافق أوالافتراق بين قيمتي وينر باتجاهات المسح السمتي

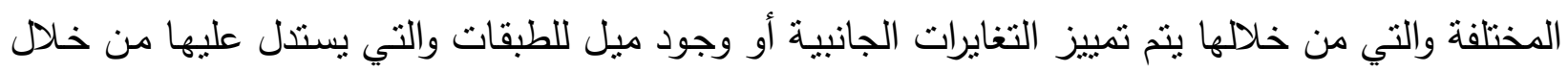

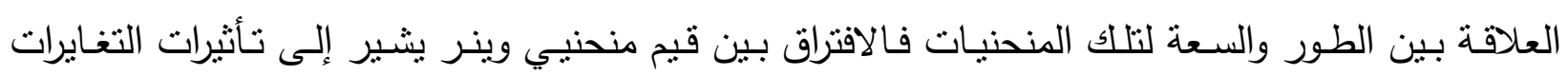

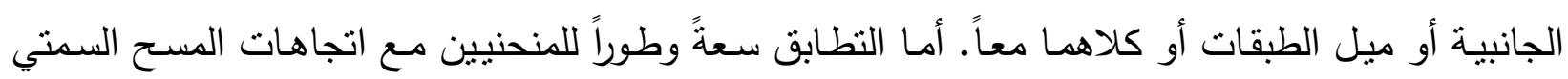

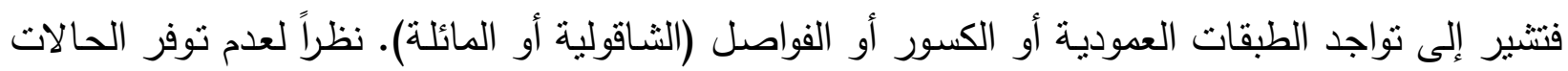

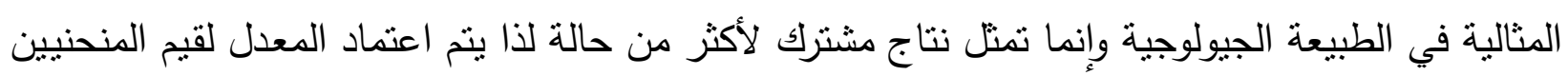




\section{مروان متعب و يوسف فرنسيس اقليمس}

باتجاهات السمت المختلفة (RDm) حيث من خلالها يتم تمييز أنواع اللاتماثل والقيم اللاتماثلية لها، كما يتم تحليل الخطأ الازاحي وتحليلات المدى والتي تميز بين التغايرات الجانبية وميل الطبقات بوضوات النواعل

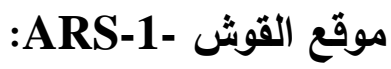

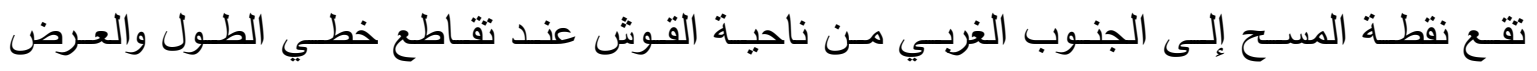

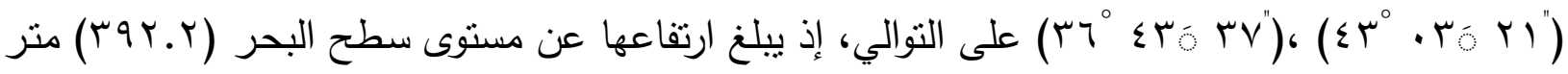
وقد اختير الموقع بين طيتي القوش في الثمال و قند في الجنوب فوق سطح المنحدر التراكمي القدمي (Foot accumulate dip surface) (الداغستاني، 1 . . r) نحو بحيرة سد الموصل (الثكل ()).

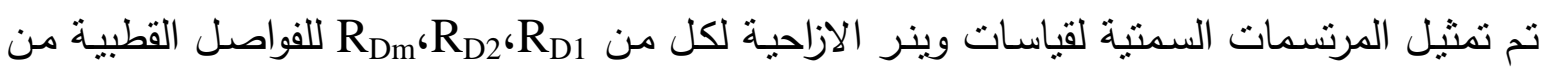

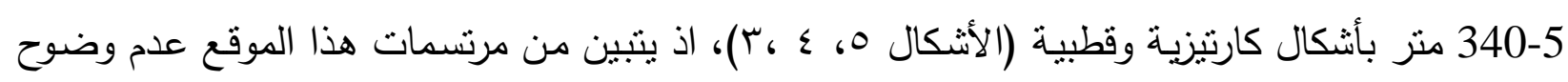

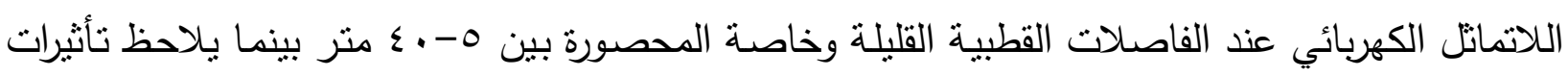

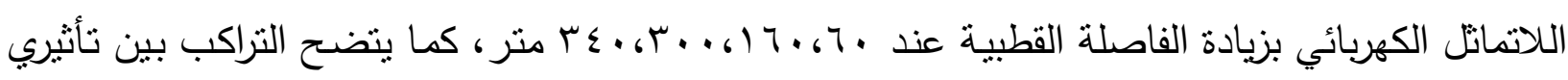

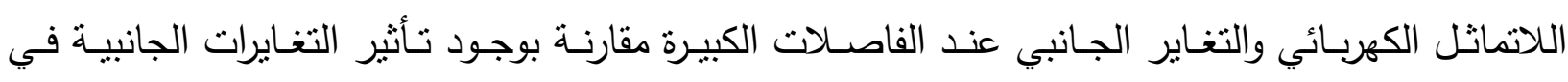

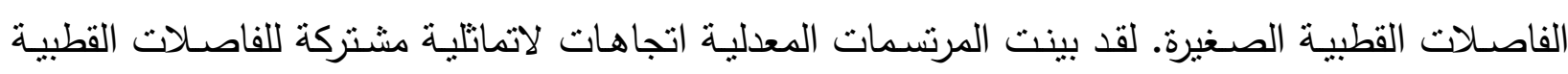

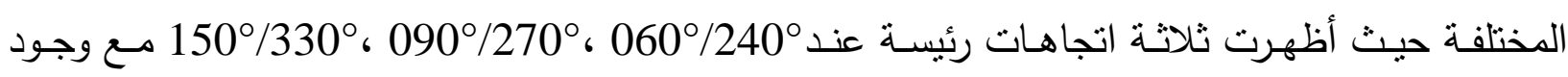

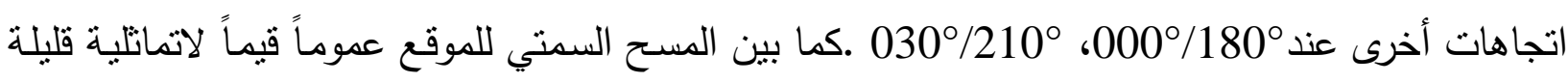

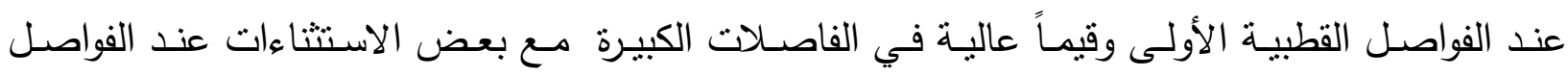

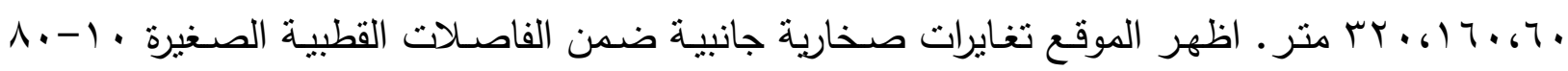
متر مع ملاحظة الاستمرار التراكبي بين الثأثيرين.

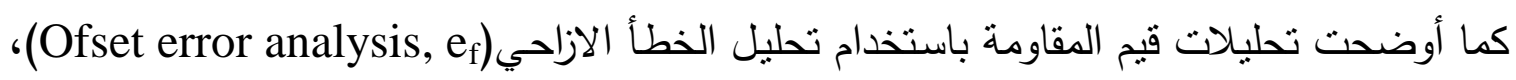

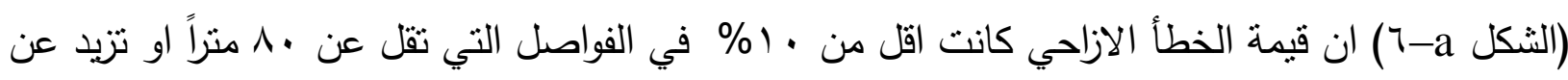

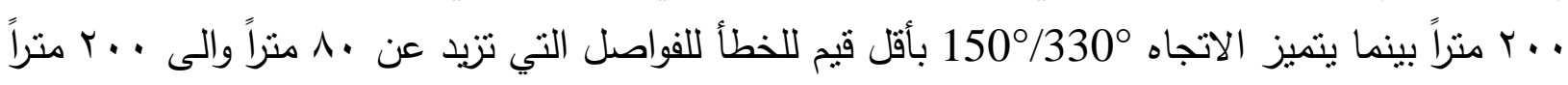

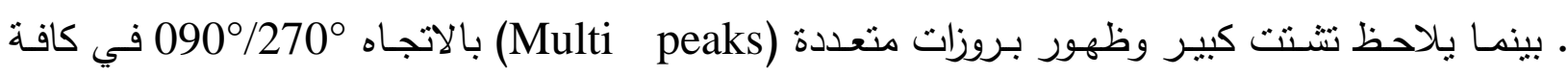
الفاصلات المستخدمة في المسح الازاحي.

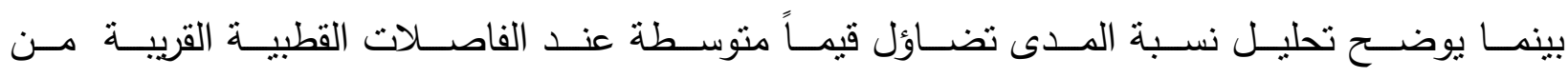

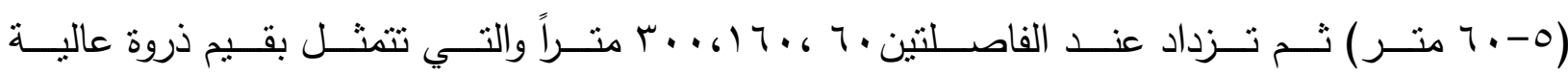

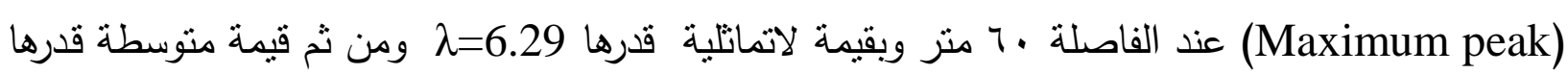

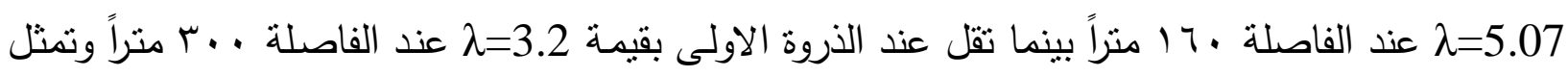

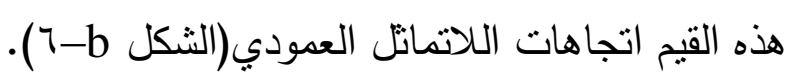

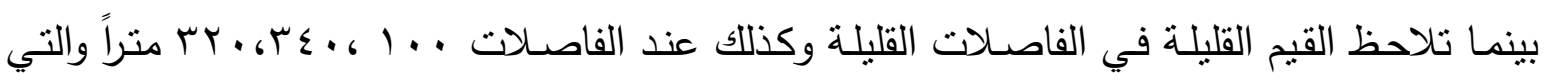
تمثل ناثير اللاتماتل الكهربائي المائل المتراكب مع التغايرات الجانبية او تغايرات جانبية منفردة. 

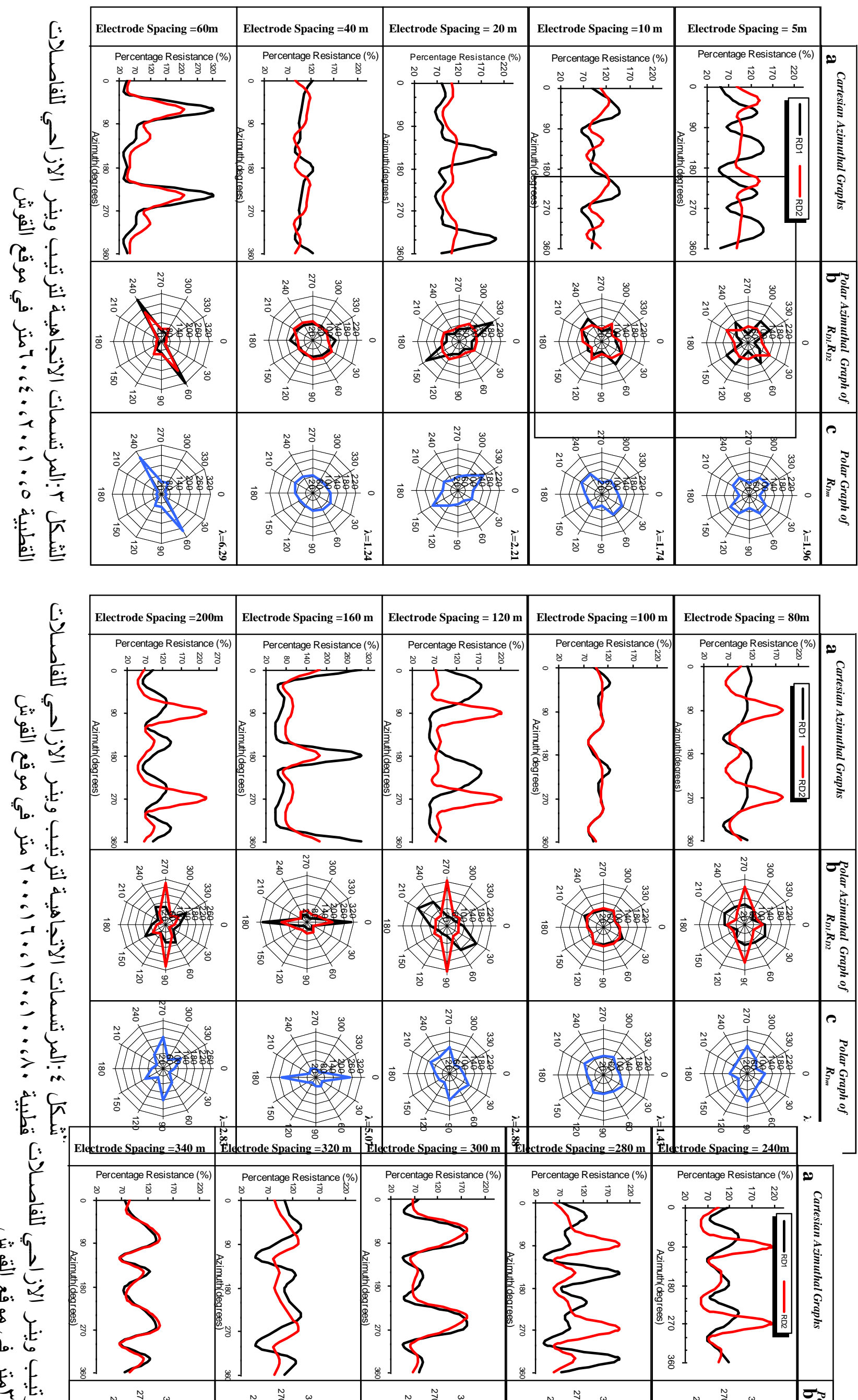
مروان متعب و يوسف فرنسيس اقليمس

: ARS-2- موقع بوزلان

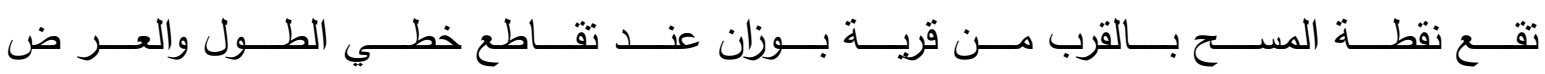

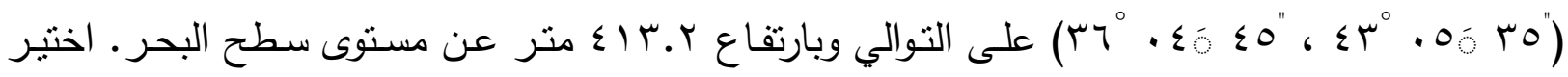
الموقع بين الجزء الثرقي من طية القوش شمالاً وطية قند جنوباً حيث ينحدر السطح التراكمي القدمي باتجاه 
الثمال الغربي إلى الجنوب الثرقي (الداغستاني، V . . †) نحو منابع وادي الخوصر الذي يصب في نهر دجلة الذي يمر بمدينة الموصل.

يتصـف موقــع بـوزان (ARS-2-) بوجـود تخـايرات صــخارية جانبيـة فـي الفاصــلات القطبيـة

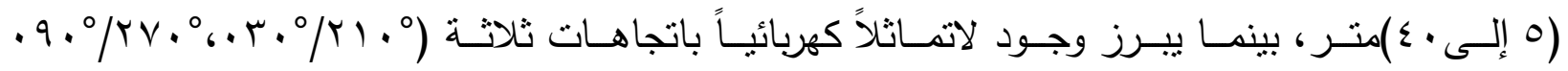

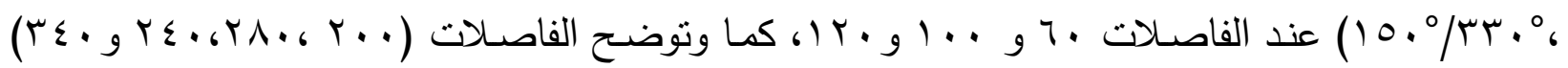

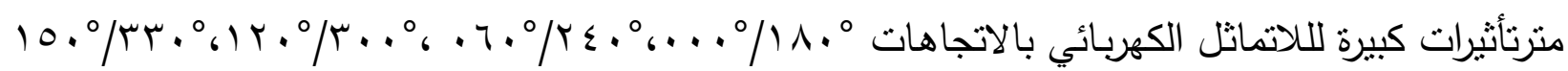
مع وجود تداخل وتراكب مع تأثيرات التغايرات الجانبية. وتبين الفاصلات ( • م و . . ب و • بr) متر التأثير

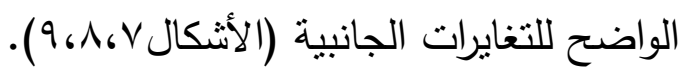
وعموماً يبين الموقع استمرار تاثيرات اللاتماتل الكهربائي العمودية والمائلة في عدة فواصل قطبية حيث

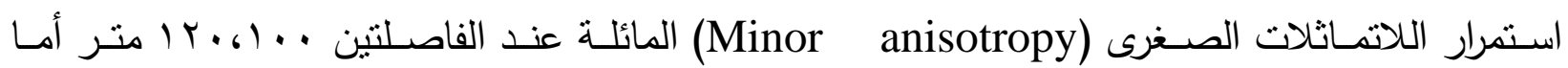

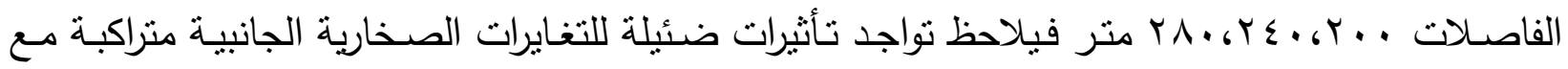

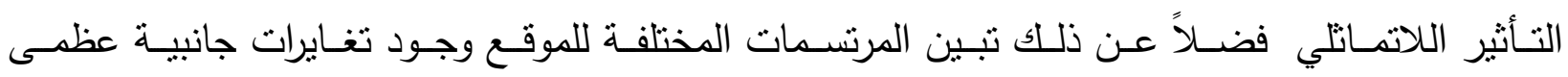
للفاصلات القطبية ه- • 7 منز حيث يستدل عليها من افتراق المنحنيين في (Major lateral variations) اتجاهات المسح السمتي المختلفة كما تم تحديد قيم لتغايرات صغرى (Minor lateral variation) عند

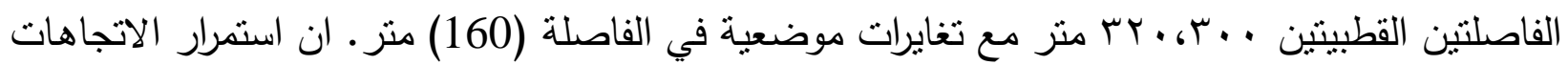
اللاتماتلية والتغايرات الجانبية لعدة فاصلات يمكن أن يعزى إلى انطقه كهربائية منتـابه أو الحدود الفاصلة بين التكوينات الجيولوجية في منطقة الدراسة والتي تشمل ترسبات العصر الرباعي الحديثة وتكويني مقدادية وانجانة.

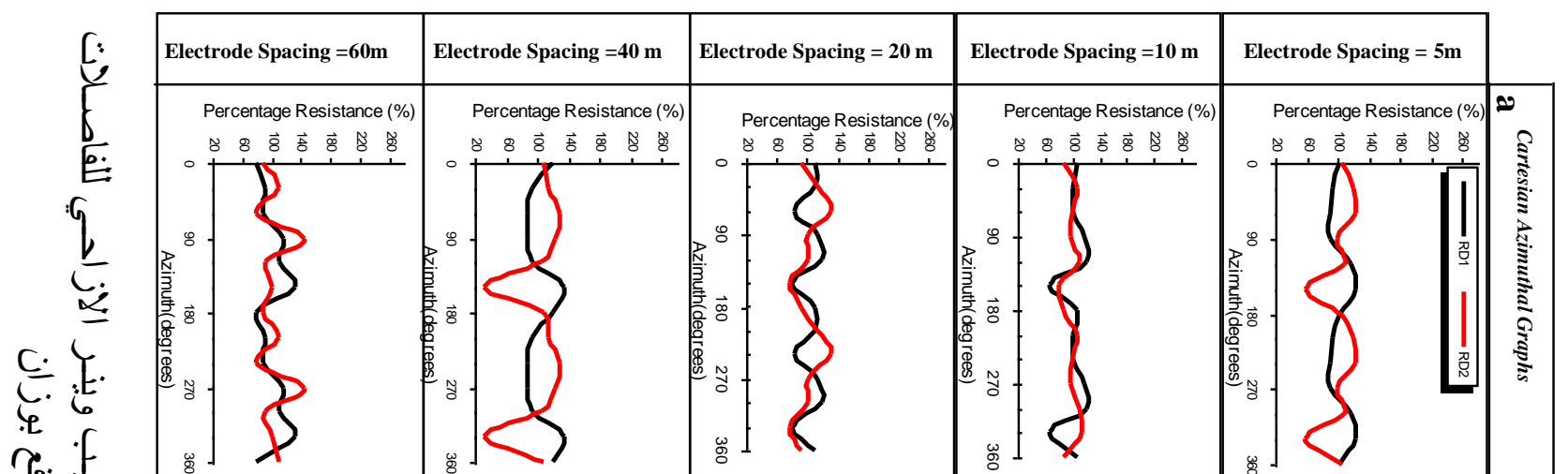


مروان متعب و يوسف فرنسيس اقليمس

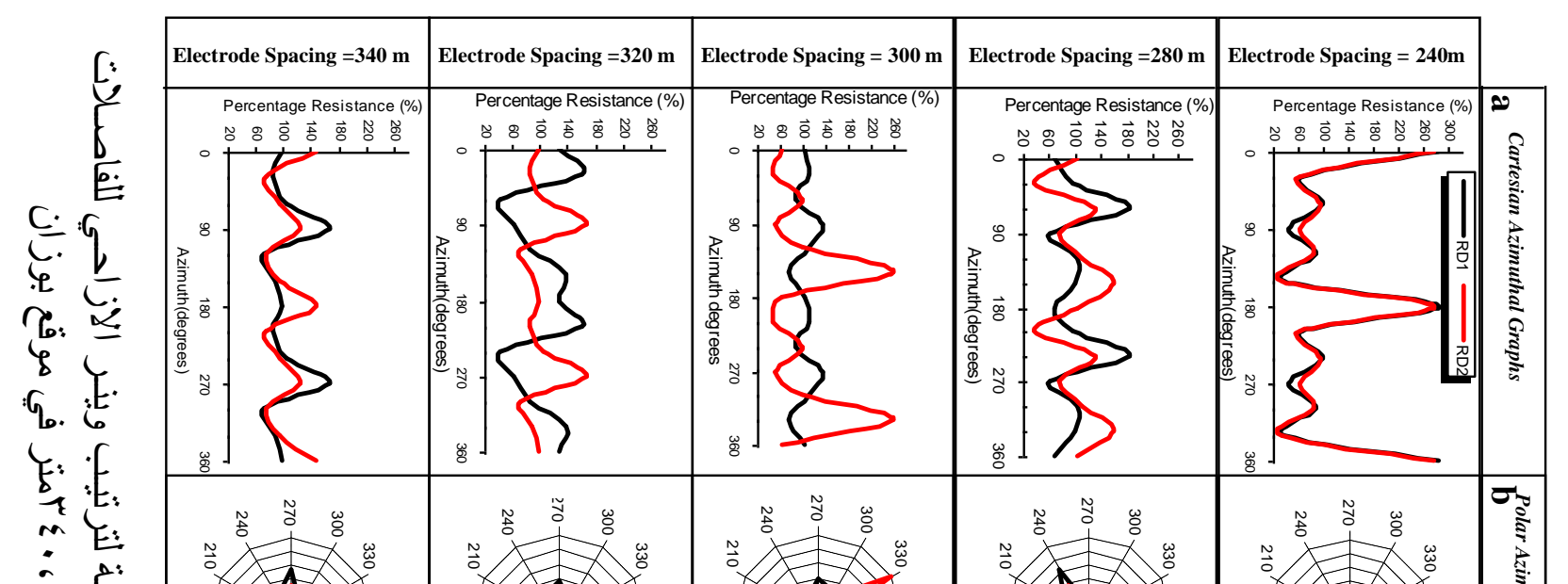


لقد أوضح تحليل الخطأ الازاحي (الثكل a- · ) أن هناك تبايناً بالقيم بالاتجاهات المختلفة لموقع

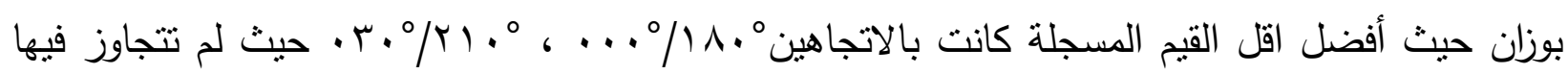

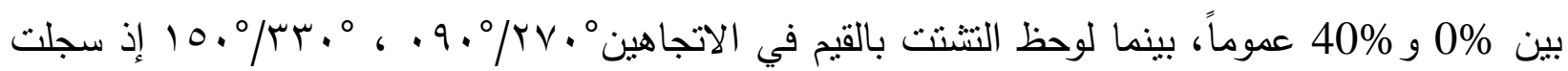

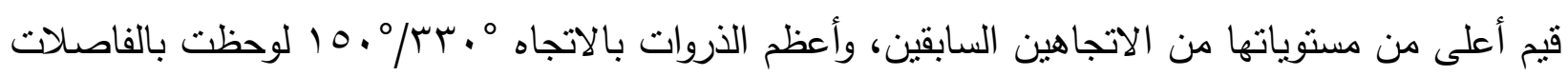

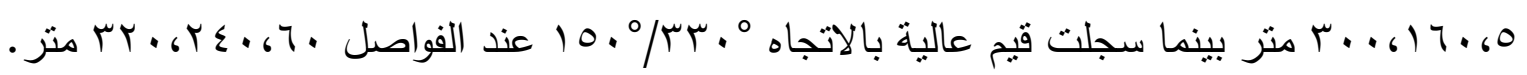


يتضح ان نسبة المدى البارزة جداً (Maximum Peak) تمنل اللاتمانل العمودي ذو القيمة اللاتماثلية مقدارها 0.9 0، بينما تتضائل القيم ليصبح اللاتمانل مائلاً كما في الفاصلة القطبية ، ــامتراً. ويلاحظ أيضاً القيم القليلة التي لا تتجاوز 50\% للفاصالات القليلة حيث تمنل التغايرات الجانبية الصخارية في الفاصلات

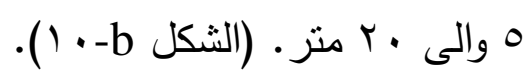

\section{: ARS -3- موقع بيبان}

اختير موقع المسح في أقصى الجهة الثرقية من قرية بيبان ،عند تقاطع خطي الطول والعرض "

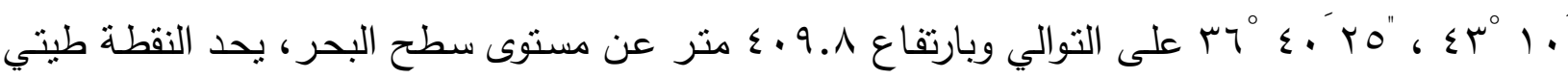
القوش وعين سفني شمالاً وطية قند جنوباً (الثكل (-1 ) وينحدر السطح التراكمي القدمي باتجاه الثمال الغربي - الجنوب الثرقي حيث تتجه الوديان المحيطة بنقطة المسح. يلاحظ بمقارنة المرتسمات الكارتيزية لموقع بيبان في الفواصل القطبية ه- ـ ـ متر تأثيرات التغايرات الجانبية الضئيلة وذلك من خلال ملاحظة السعة القليلة لمنحنيي القياس(R2، R • 7 متز بتزايد تأثير التغايرات الجانبية من خلال السعة الكبيرة لقيم النسب المئوية للمقاومة مما يدلل على تغير في الخصائص الصخارية والانتقال من تكوين مقدادية إلى تكوين انجانة. كما يلاحظ بروز اتجاهات

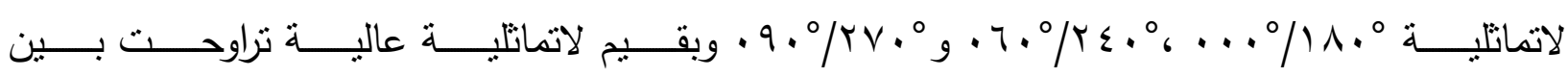

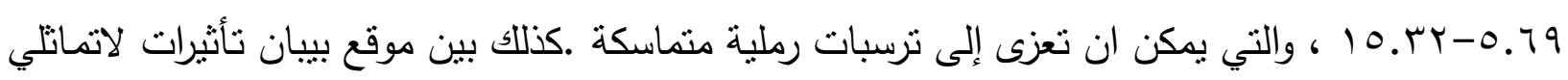

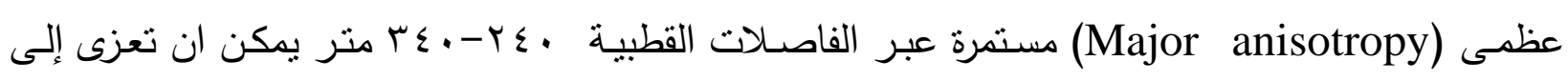

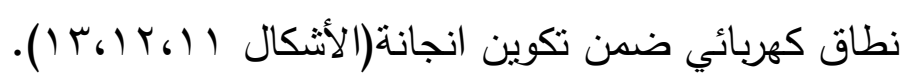

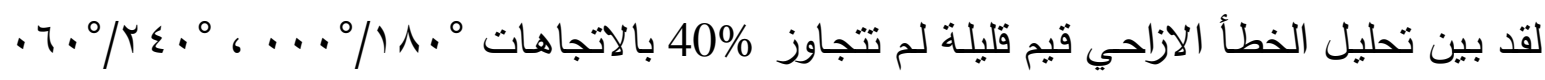
، • • التي تتراوح بين 0\% و 30\% لتمثل اقل التغايرات الصخارية فيه باستنثاء الفاصلة القطبية . . . مثر حيث تصل نسبة الخطأ إلى حوالي 50\% والتي تمثل تاثير اللاتماثل الكهربائي ـ أما بقية الاتجاهات فتتمثل بقيم عاليـة تصل إلى 90\% والتي يعتقد فيها زيادة اللاتماثل الكهربائي والتغايرات الجانبيـة الصـخارية وخاصـة

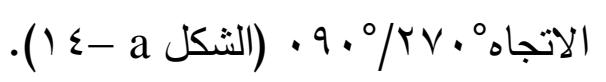

بينمـا يوضـح تحليل نسبة المدى تضـاؤل قيمها في الفاصـلات القطبية ه والى ، ع متر لتنقل إلى

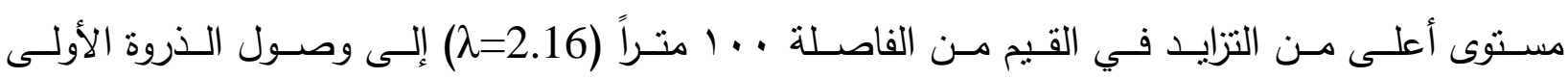
بمعامـل لاتمـاتلي قدره (First peak)

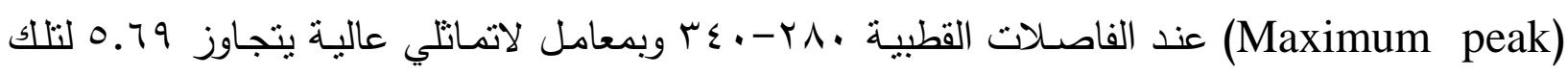


الفاصلات القطبية. بينما يتوسط تلك الفاصلات قيم قليلة لمعامل اللاتماثل تتمثل بتأثير التغايرات الجانبية

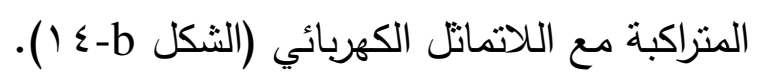

\section{تمييز تراكيب الكسور:}

ساعد تطور تقنيات مسوحات المقاومة الأرضية الجيوفيزيائية على اكتشاف الكسور في الطبقات

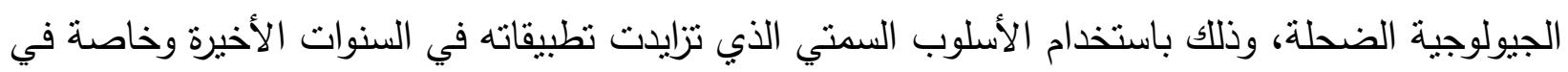
المناطق التي لا تتواجد فيها منكثفات للتكاوين الجيولوجية. ان تمييز تلك الكسور وتحديد خصائصها بعتبر

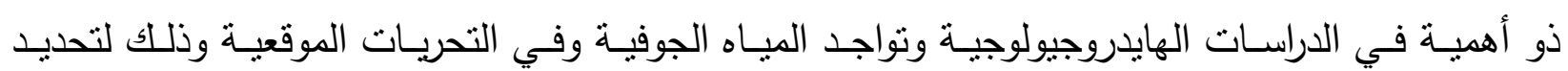
صلاحيات الأسس في تتفيذ المشاريع الهندية الإستراتيجية كالسدود والمنشآت والمشاريع الكبيرة. هناك العديد من الطرق لاكتثاف الكسور معتدة على نوعيتها، ففي المقياس الكبير ومن خلال الصور الجوية والمرئيات

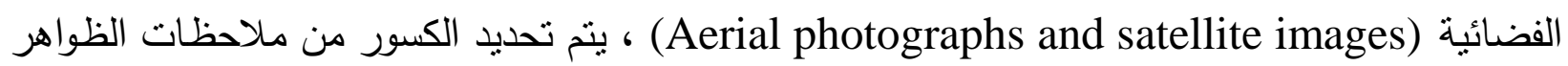
الخطية (Linear features) كالاختلاف التتاغمي في التربة (Tonal variation in soil)، واصطفاف أنماط النباتات(Alignment of vegetation patterns)، وقطوعات الجداول المستقيمة Straight) stream segments or valleys) فهنالك طرق أخرى في اكتثاف الكسور عبر الأعمال الحقلية المبانشرة والتي من خلالها يتم تحديد أنواعها ضمن التكاوين الجيولوجية عبر منكثفاتها الصخرية.

\begin{tabular}{|l|l|l|l|l|l|l|}
\hline Electrode Spacing $=60 \mathrm{~m}$ & Electrode Spacing $=40 \mathrm{~m}$ & Electrode Spacing $=\mathbf{2 0} \mathrm{m}$ & Electrode Spacing $=\mathbf{1 0} \mathrm{m}$ & Electrode Spacing $=5 \mathrm{~m}$ \\
\hline Percentage Resistance (\%)
\end{tabular}


مروان متعب و يوسف فرنسيس اقليمس

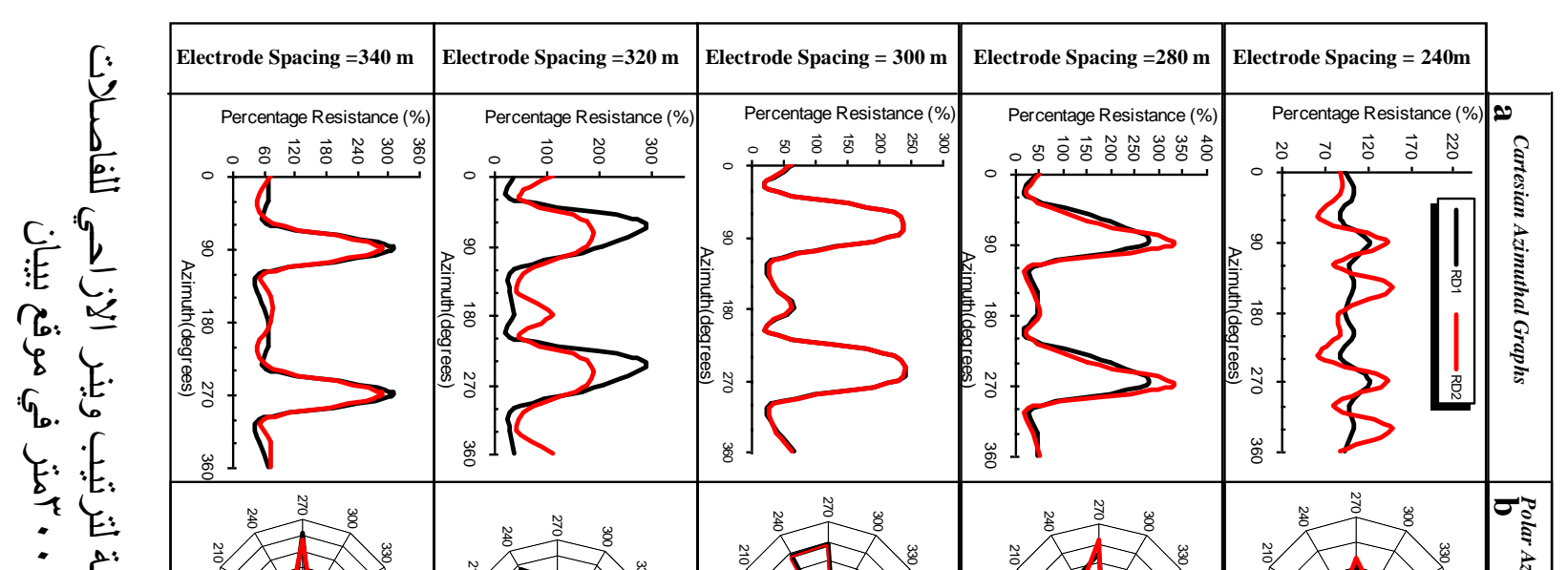




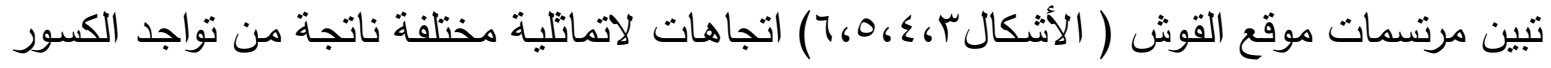
المختلفـة ضــن تكوينـات المقداديـة وانجانـة، حيـث يمكن تصــنيفها اعتمــاداً على اتجاهاتهـا وعلاقاتهـا مع محور طيتي القوش ودهقان القريبتين من موقع المسـح، إذ تم تمييز أنواع من الكسور العمودية والموازية

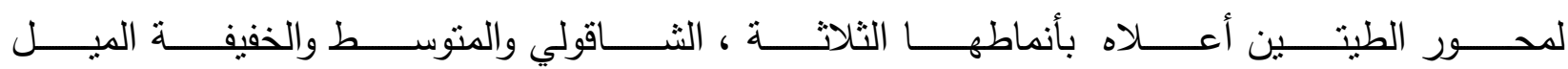
في الاتجاهْ • Vertical (V), Medium (M) and Gently(G) dip) 


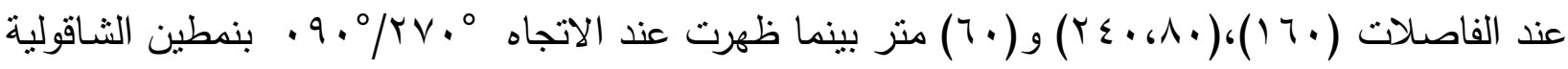

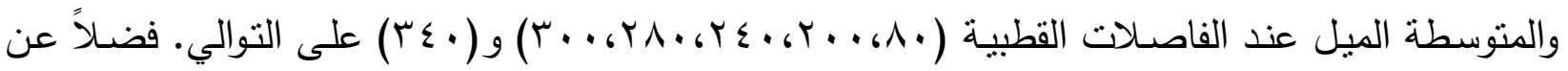
تمييـز مجـاميع الفواصـل القصـية بأنماطهـا الثلاثنة أعـلاه وبمجموعتيها الحـادة حـول المحسور (a) بالاتجـاه

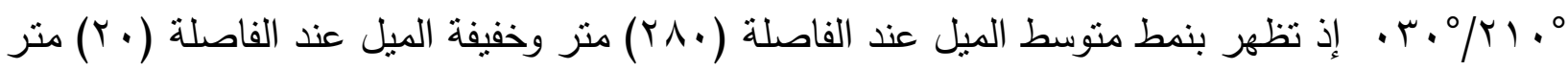

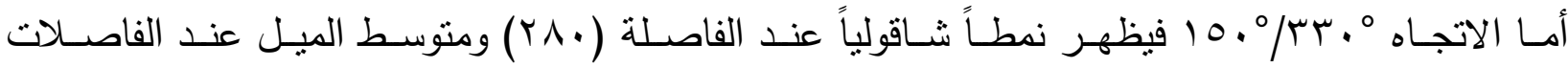

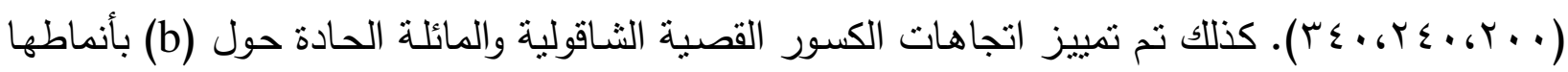

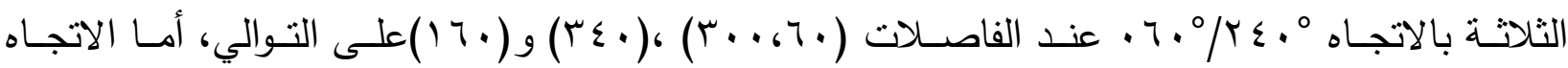

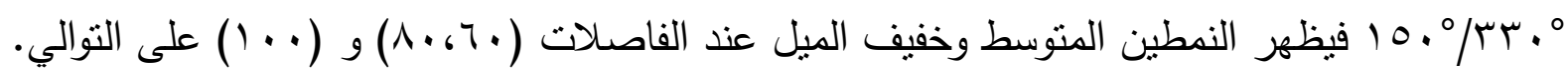
وتبرز الدراسة الإحصائية لموقع القوش (الثكلA-15) اتجاهات رئيسة ثلاث للكسور ، الموازي لمحور الطية والقصي الحاد حول (a). ويمثل (الجدول () ملخص لأنواع الكسور المختلفة واتجاهاتها. : موقع بوزان

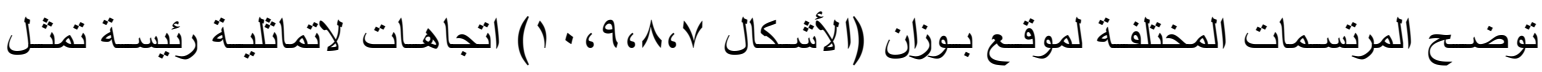
الفواصل والكسور الثدية والقصية حيث تمثل المجموعة الأولى (ac) العمودية على محور طية القوش

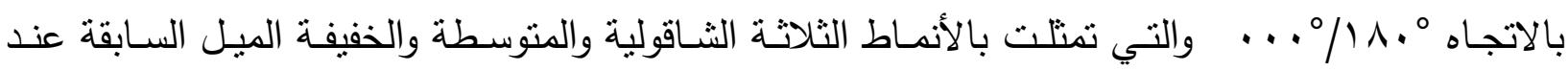

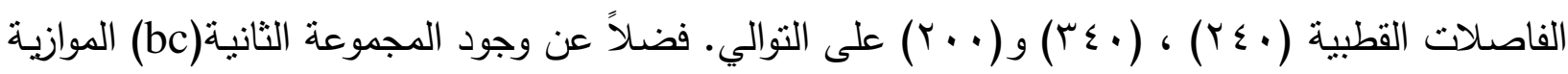

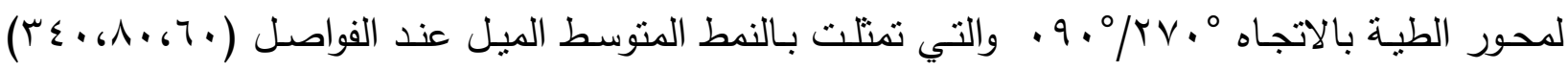

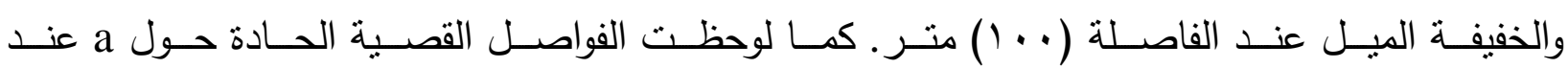

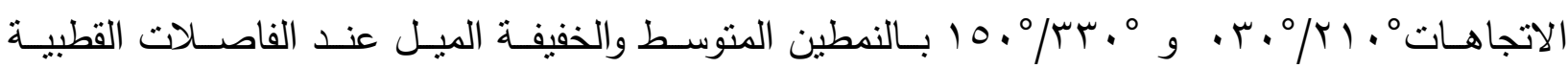

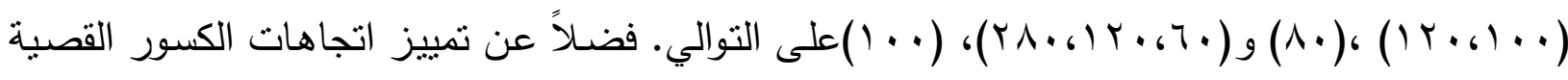

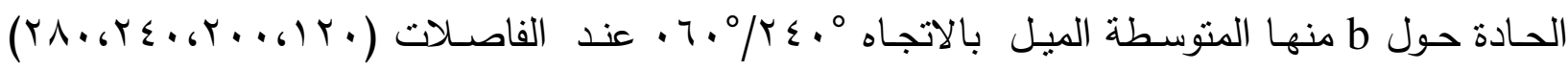

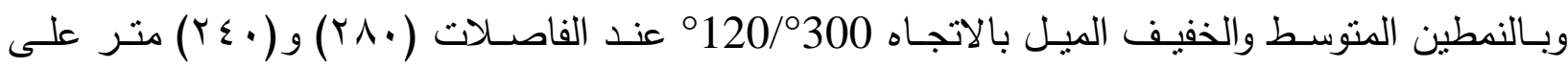
التوالي.

وتبرز الدراسـة الاحصـائية لترددات الكسور في الموقع اتجاهات ثنلاثتة رئيسـة ومشـابهه لموقع القوش

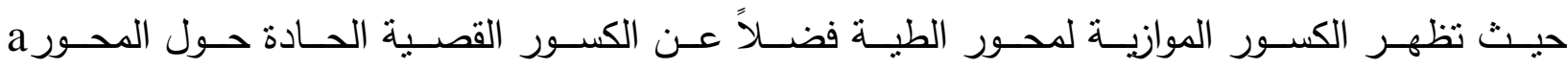
(الشكل 15-B) ويمثل (الجدول 1) ملخص لأنواع الكسور المختلفة واتجاهاتها. موقع بيبان:

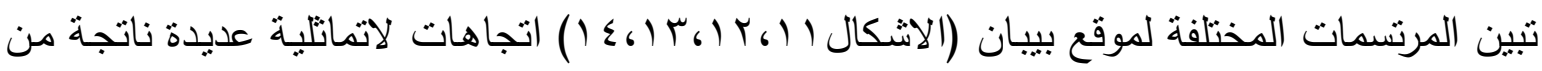
وجود الكسور في طبقاتها الصـرية ضمن تكويني المقدادية وانجانـة حيث أمكن تمبيز أنواع من الكسور

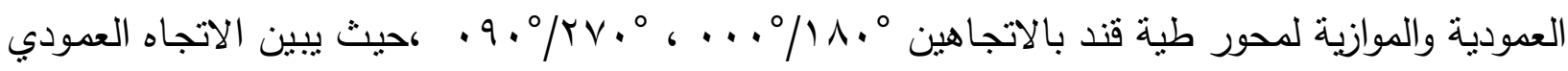

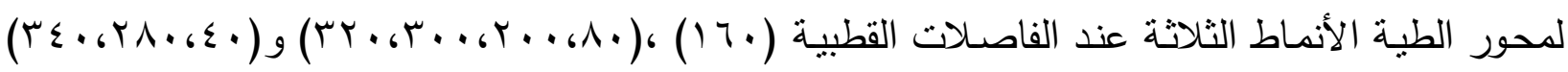




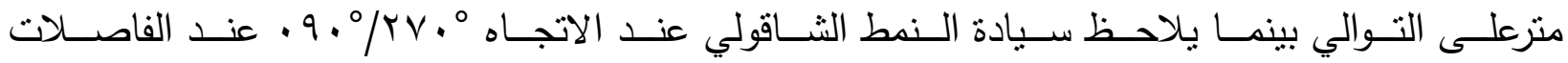

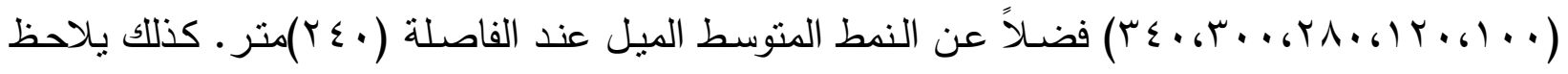
تواجد مجموعتي القص، الأولى الحادة حول المحور(a) فضـلاً عن المتوسطة والخفيفة الميل بالاتجاهين

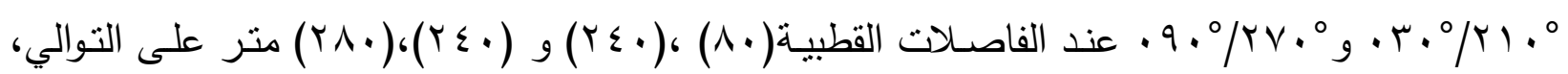

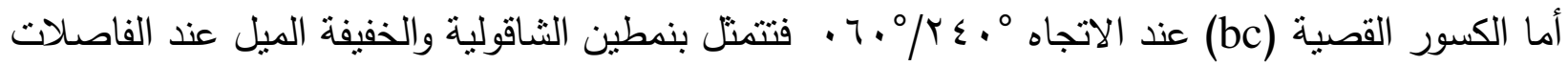

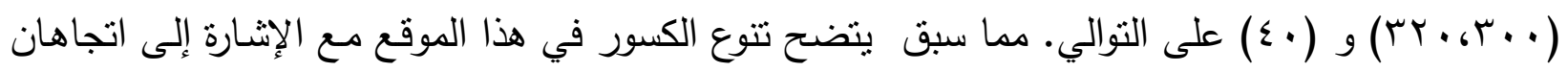
رئيسـان العمـودي والمـوازي لمحور طيـة قند (الثـكلC-15) و(الجدول 1) يمثل ملخص لأنـواع الكسور المختلفة واتجاهاتها.

\section{التغايرات الجانبية في منطقة الاراسة.}

أبرزت المرتسـمات المختلفـة وجود لاتمـاثلات كهربائبة كاذبـة ناشئة عن تـاثير التغايرات الصـخارية الجانبية في اتجاهات مختلفة حيث تتواجد تردداتها بكثرة عند الفاصلات القطبية المحصورة بين 0- ب ا متر عند اغلب مواقع المسح السمتي. أثتتـت الدراسـة الإحصـائية للتغايرات الجانبيـة نباينها من منطقة إلى أخرى حيث يبين(الثكل 15) الاتجاهات المختلفة للاتماتل الكهربائي الكاذب، إذ يبين موقعي القوش وبوزان تأثيرات التغايرات الجانبية عند

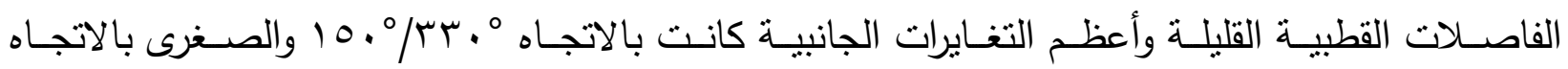

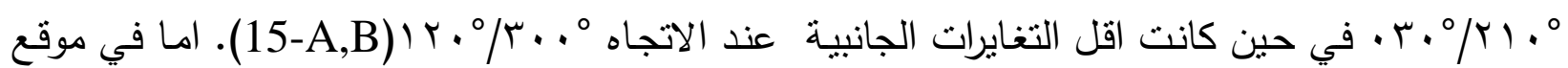

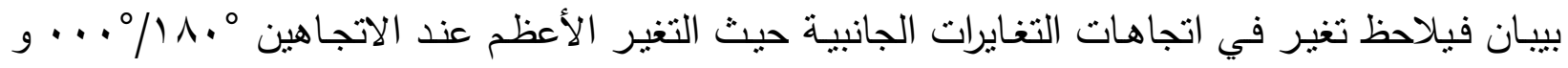

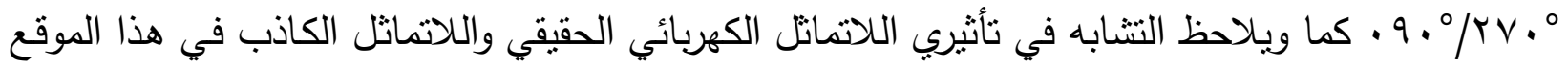

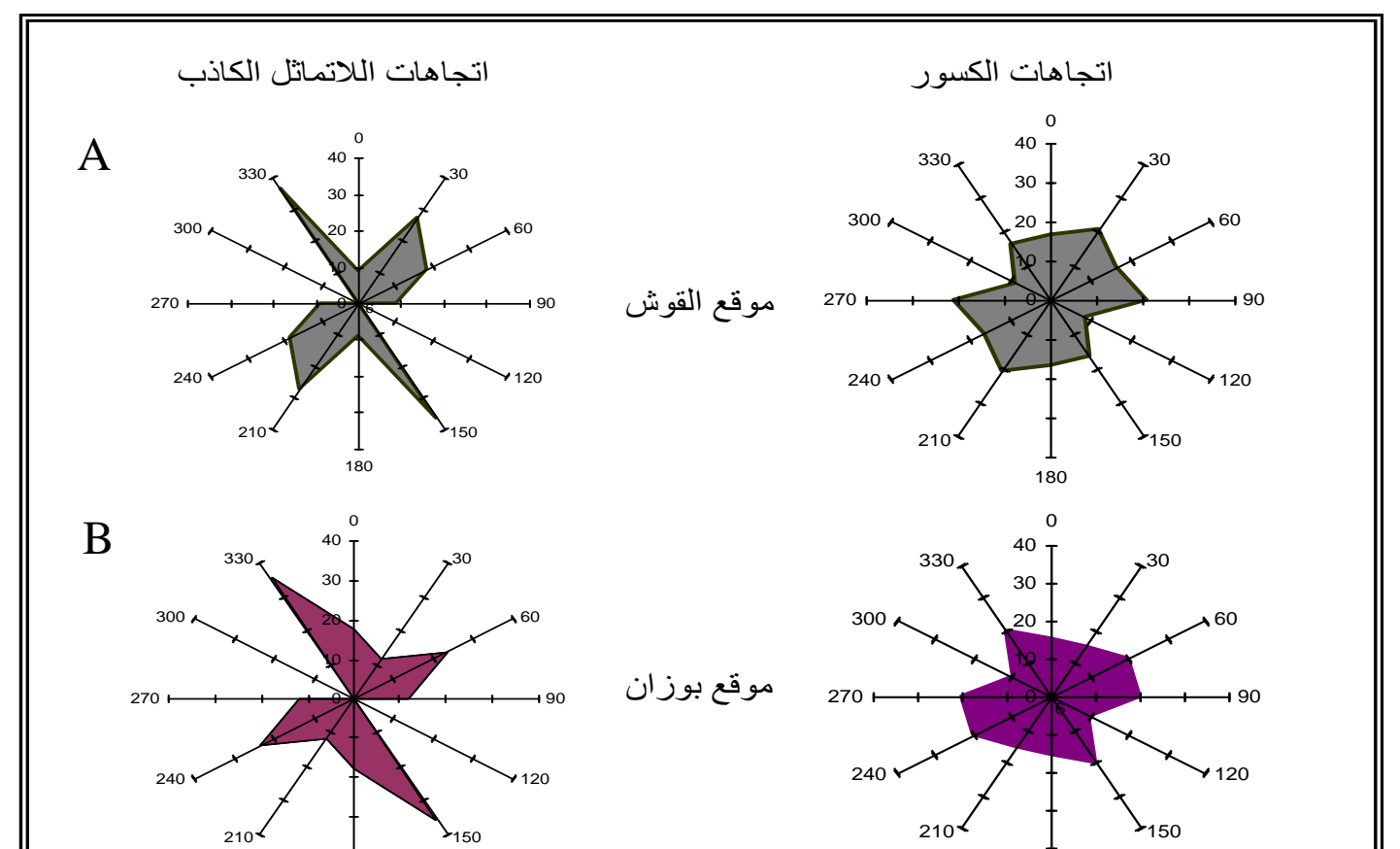


الجدول ا : :مقارنة اتجاهات الكسور وتردداتها وفق الدراسة الحالية والدراسات السابقة.

\begin{tabular}{|c|c|c|c|c|c|c|c|}
\hline \multicolumn{4}{|c|}{ تردد الفواصل المائلة } & \multicolumn{2}{|c|}{ تردد الفواصل العمودية والموازية } & \multirow{3}{*}{ المستح } & \multirow{3}{*}{ الار اسة } \\
\hline \multicolumn{2}{|c|}{ الحاد حول (b) } & \multicolumn{2}{|c|}{ (a) الحاد حول (a) } & مجموعة (bc) & مجموعة(ac) & & \\
\hline $14.0 / 4 \ldots \circ$ & $.7 .0 / Y \leqslant .0$ & $10.0 / 4 r .0$ & $. r .0 / Y 1.0$ & $.9 .0 / Y \vee .0$ & $\ldots \circ / 11.0$ & & \\
\hline 9 & iv & TY & IV & YY & $\pi$ & 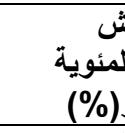 & 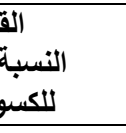 \\
\hline 1. & $r$. & $r$. & $r$. & 10 & 10 & ان & النسبة بو \\
\hline 1r. & $.81 \% / 71 \circ$ & $107 \%$ & $.11^{\circ} / 7 \wedge^{\circ}$ & $.9 V^{\circ} / \Lambda r^{\circ}$ & $\cdots r^{\circ} / \wedge \varepsilon^{\circ}$ & هقان 1999 (19. & (السامرائة \\
\hline 0.0 & 7.0 & r.r & 7.7 & r.Ao & 1.1 & معياري \% & الانحراف \\
\hline$\varepsilon$ & r & $\varepsilon$ & 9 & rq & $\varepsilon r$ & 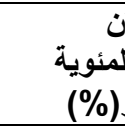 & النسبة بل ابل \\
\hline
\end{tabular}

\section{المناقشة والاستنتاجات}

لقد اكتسبت تقنية المسح المقاومي السمتي وعبر فواصل قطبية مختلفة اهمية كبيرة في تحديد الكسور والفواصل وتعد الدراسة الحالية الأولى من نوعها في العراق باستخدام طريقة المسح العميق بتقنية وينرالسمتية الازاحية ـ أبرزت مرتسمات مواقع منطقة الدراسة وجود ترددات واتجاهات وميل متباين للكسور حيث اظهر موقع القوش مجـاميع عديدة للكسور والفواصـل الموازيـة والعموديـة لمحور الطيـات والتي كانت من النوع الثـاقولية والمتوسطة الميل (الجدول ب- r) كما تبين سيادة ترددات الاتجاه العمودي لمحور طيتي دهقان

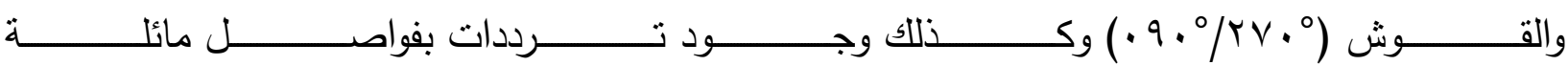


بالاتجاهـات . (Oblique joints)

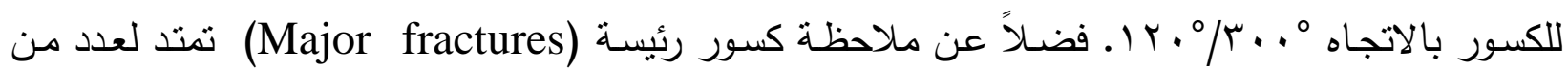

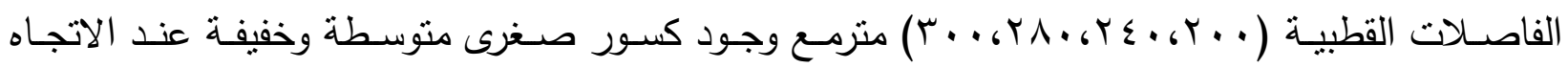

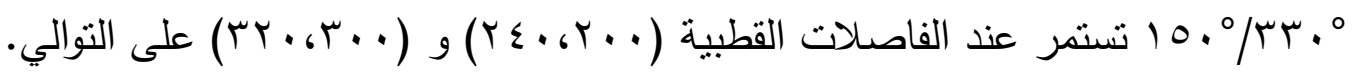
كمـا اظهر موقـع بوزان ترددات واتجاهـات مقاربـة لمـا ذكر في موقع القوش، إذ يلاحظ استمرار

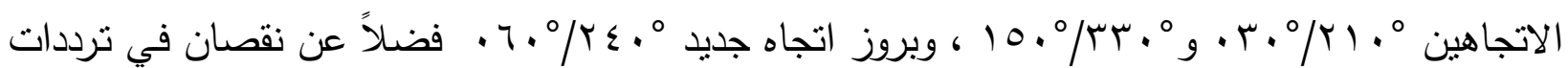

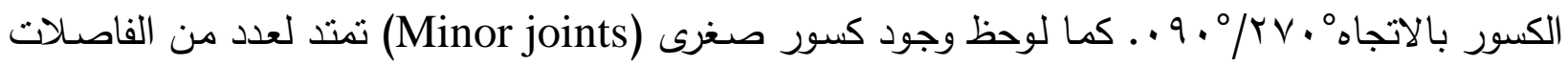

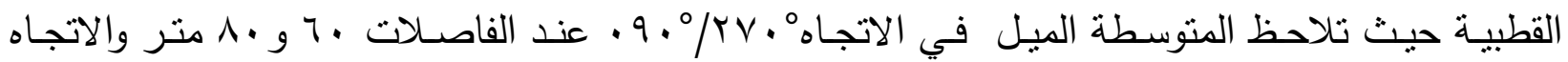

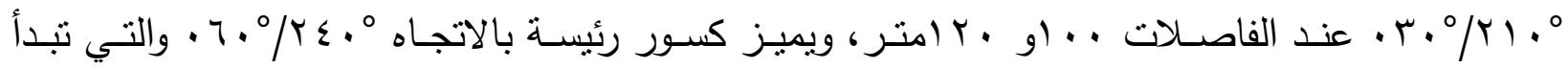

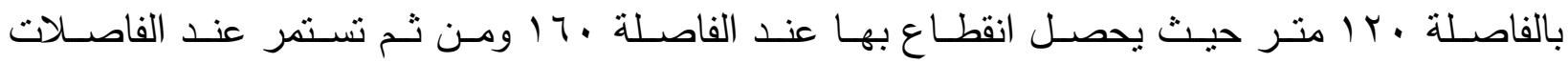

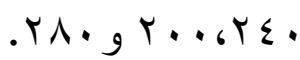

تم إجراء مضـاهاة لاتجـاه وميل الكسور في موقعي القوش وبوزان وفق الدراسـة الحاليـة مـع دراسـة

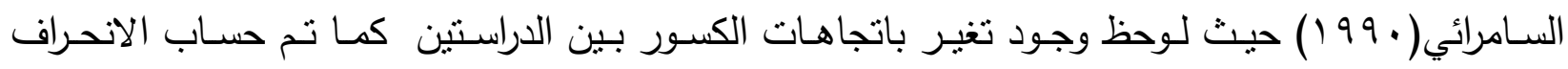
المعياري الأقصى وتبين انه يساوي 0.083 ،كما تم حساب الانحراف المعياري لكل اتجاه وقورنت المعلومات

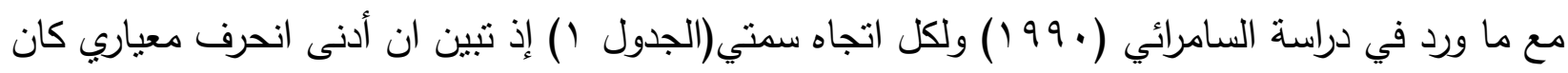

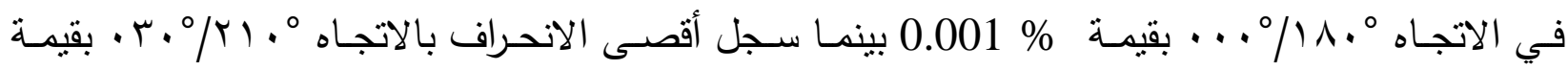
0.066\% وهو ضمن النسبة القصوى المشار اليها أعلاه. كما تبين أن اغلب الكسور والفواصل كانت ذات اتهات ميل شـاقولي ومنوسط باستثناء القسم القليل منها كان ذات ميل خفيف وهذا يتوافق مـع دراسـة السـامرائي اعلاه.

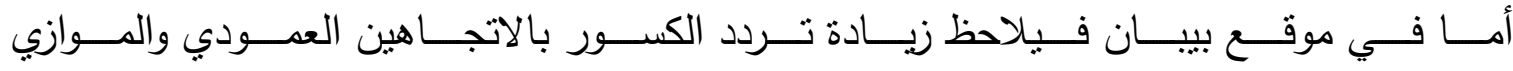

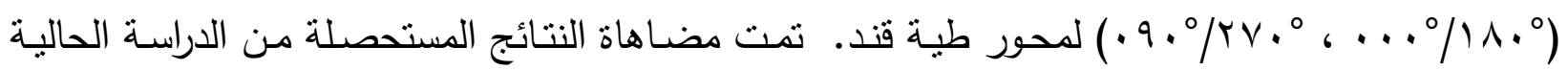
للقيم الحقلية الدقاسة في طيتي قند وتبين نواجد أربعة فواصل رئيسة للكسور والفواصل إذ أظهرت ترددات

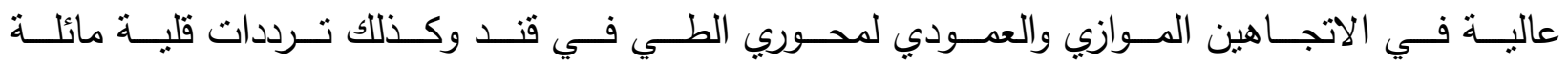

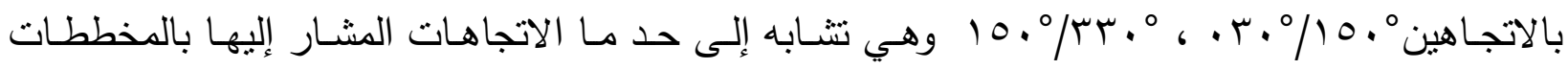

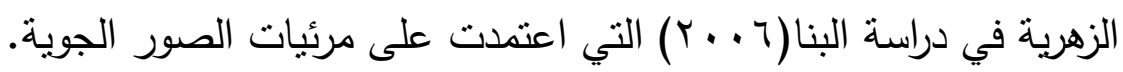

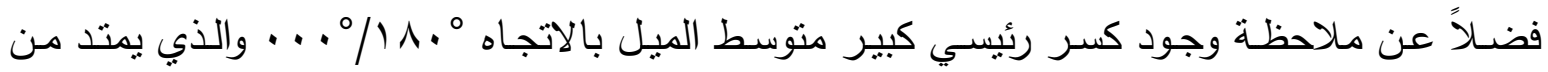

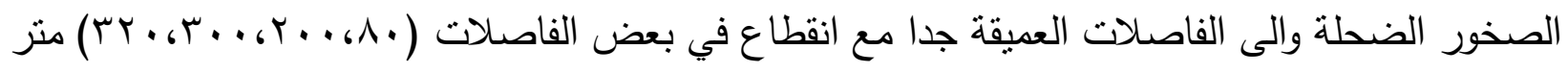

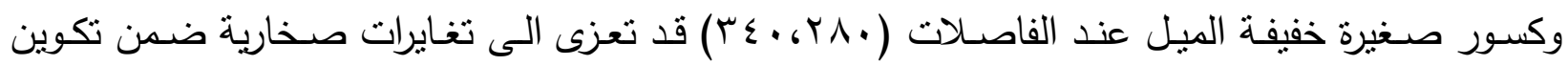

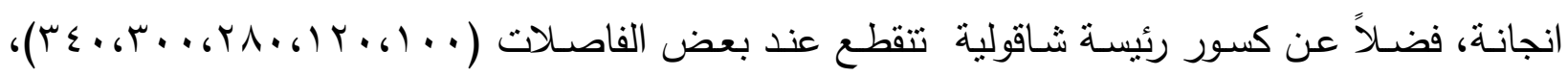

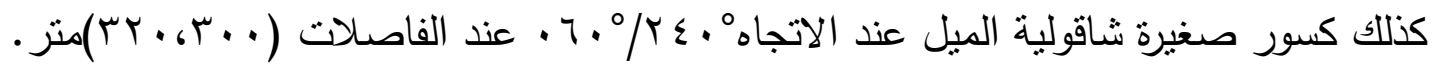




\section{الاستنتاجات}

أبرزت الدراسة الإحصائية لترددات الكسور في منطقة الدراسة اتجاهات رئيسة للكسور وخاصة الكسور

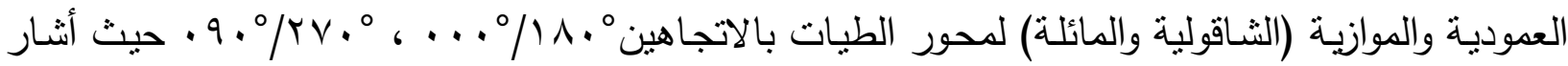
(Ameen, 1979) لتزامن الترسـيب في بعض التكاوين في الطبـات البسـيطة وخاصـة لمنكثـفات تكـويني المقداديـة وانجانـة وتتطابق مع الدراسة الاقليمية للفواصل في ترسبات

عصر الترشري لنطاق الطيات في إيران والعراق وفق (Ameen, 1979) والتي أثـارت الى التردد الواسع للفواصل الثدية (الموازية والعدودية) لمحاور الطيات في هذه المناطق.

\section{المصادر العربية}

البنا، ريان غازي ذنون، r . . r . جيومورفولوجية تركيب قند شمال العراق باستخدام تقنيات التحس النائي.

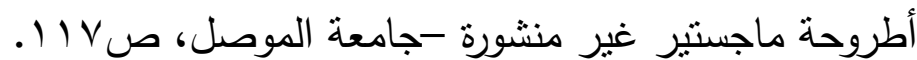

الراشدي، محمد علي مال الله حسين ج . . r. دراسـة رسوبية لتكوين انجانة في طية قند - شمال العراق، أطروحة ماجستير غير منشورة، كلية العلوم، جامعة الموصل.

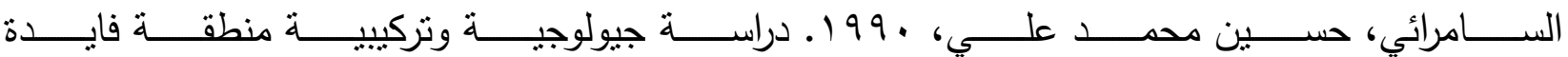
(طية دهقان المحدبة). اطروحة ماجستير ، كلية العلوم، جامعة الموصل، صس إ) متعب ،مـروان، محضـر باشـي،ثابت والجريسي، بشـار 9 . . r. دراسـة بيئيـة لحقل المشـراق - ا في ضـوء

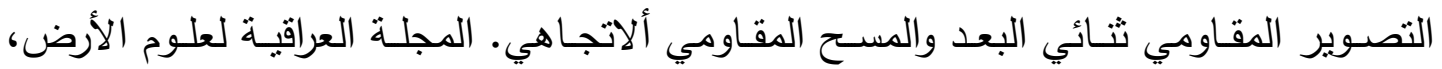
المجلد 9، العدد ب، ص • •-10 1.

\section{المصادر الأجنبية}

Al-Daghastani, H. S., 2007. Geomorphologic Map of Nineveh Governorate - NW Iraq Using Visual Image Interpretation. Raf. Jour. Soci., Vol. 18, No. 1, pp. $81-90$.

Al-Kadhimi, S., 1996. Tectonic Map of Iraq, Geo Survey, Printed and Published by the State Establishment of Geol. Surv. and Mining, Baghdad, Iraq.

Ameen, M. S., 1979. Regional Investigation of Geoflexture and Tectonic Analysis in the Simple Folds Zone of Iraq, M. Sc. Thesis (Unpublished), Mosul Univ., Iraq, $236 \mathrm{p}$. 
Boris. M., 2005. Azimuthal Resistivity to Characterize Fractures in the Battleford Formation at the King Site, Birsay ,Saskatchewan. M.Sc University of Saskatchewan, 77p.

Buday, T. and Jasim, S. Z. 1987. The Regional Geology of Iraq, Vol. 2, (Tectonism and Metamorphism) GEOSURV., Baghdad, Iraq, $352 \mathrm{p}$.

Busby J. and Jackson P. 2006. The Application of time-lapse Azimuthal Apparent

Resistivity for the Prediction of Coastal Cliff Failure. Journal of Applied Geophysics. Vol 59, Issue 4, pp. 261 - 272.

Busby, J., (2000). The Effectiveness of Azimuthal Apparent - Resistivity Measurements as a Method for Determining Fracture Sstrike Direction: Geophy. Prosp., Vol. 48, pp. 677 - 695.

Sissakian, V. K., Hagopian, D. H., Hassan, E. A., 1995. Geological Map of Al-Mosul Quadrangle, Sheet NO. NJ-38-13, Geosurve, Baghdad, Iraq.

Numan, N. M. S., 1997. A plate Tectonic Scenario for the Phanerozoic Succession in Iraq. Jour. Geol. Soc. Iraq, Vol. 30, No. 2, pp. 85 - 110.

Nunn, K. R., Barker, R. D. and Bamford, D., 1995, In-Situ Seismic and Electrical Measurements of Fracture Anisotropy in the Lincolnshire Chalk, Quart. Jour. of Eng. Geol., Vol. 16, pp. 187 - 195.

Rayner S. F and Bentley L. R., 2004. The Use of Electrical Resistivity Methods to Investigate Anisotropy in Fractured Groundwater System. Geophys., Vol. 64, No. 3, pp. 739 - 745.

Sauck, W. A. and Zabic, S. M., 1992. Azimuthal Resistivity Rechniques and the Directional Variations of hydraulic Conductivity in Glacial Ssediments in Bell, R. S., Ed., Symposium on the Application of Geophysics to Engineering and Environmental Problems: Soc. Eng. Min. Expl. Geophys., pp. 197 - 222.

Schumtz, M., Andriux, P., Bobachev, Montoroi, J. P, Nasri., S, 2006. Azimuthal Resistivity Sounding Over a Steeply Dipping Anisotropy Formation. A Case history in Central Tunisia, Jour. Appl. Geophys., Vol. 60, pp. 213 - 224.

Steinich, B. and Merin, L. E., 1997. Determination of Flow Characteristic in Aquifer of the Northwestern Peninsula of Yacatan, Mexico. Jour. of Hydrol., Vol. 191, pp. 315 - 331.

Watson, K. A. and Barker, R. D., 1999. Differentiation Aanisotropy and lateral Effects Using Azimuthal Resistivity Offset Wenner Soundings, Geophys., Vol. 64, pp. 739 - 745.

Watson, K. A. and Barker, R. D., 2005. Modeling Azimuthal Resistivity Sounding Over a laterally Changing Resistivity Subsurface, Near Surface Geophys., Vol. 3, pp. 3 - 11.

Wilson T., G., Heinson A. Endres and Halihan T. 2000. Fractured Rock Geophysical Studies in the Clare Valley, South Australia Expl. Geophys., Vol. 31, pp. 255-259.

Wishart, D. N. and Salter, L. D., 2007. Anistropy Characterization of Fractured Crystalline Bedrock Using Asymmetric Azimuthal Geoelectric Techniques, AGU, Vol. 88, No. 23. 
مروان متعب و يوسف فرنسيس اقليمس 